دراسة إقتصادية للجدارة الإتتاجية لأهم النباتات الطبية والعطرية بمحافظات إنتاجها الرئيسية

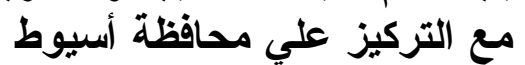

شيماء عبد الكريم مصطفي حسن ، طلعت حافظ إسماعيل، جلا علد عبدالفتاح الصغير، فالح عبد النعيم أمين قُسم الاقتصاد الزر اعي - كلية الزر اعة - جامعة أسيوط الصغير،

مقدمة:

تعتبر النباتات الطبية و العطرية من المحاصيل غير التقليديــة الهامــة ذات الإســتخدامات

المتعددة، إذ أنها تحتوي علي العديد من المركبات العضوية بالإضـافة إلي الموارد الأخري مثنـل الكربوهيدر ات و البروتينات و الدهون النباتية، وتدخل هذه المركبات العضوية في صناعة الأدوية

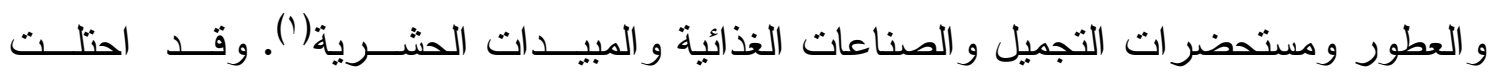
النباتات الطبية و العطرية المركز السابع في قائمة الصادر ات الزر اعية المصرية بعد صــادر ات كلا من الأرز و البرتقال و القطن و العنب و البطاطس و البصل. وقد بلغ متوسط قيمة الصادر ات

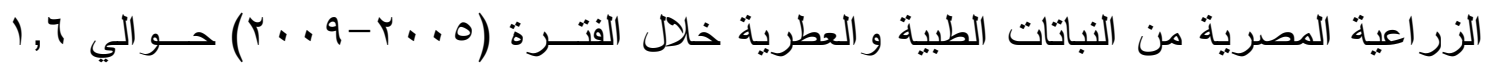
مليار دو لار وذللك بالرغم من ضآلة المساحة المزروعة من هذه النباتات في جمهوريــة مصــر العربية، حيث بلغت حو الي VY,9 ألف فدان و التي تمنل نحو 0 ., • \% مــن متوســـ المســاحة المحصولية في مصر خلال تلك الفترة و التي قدرت بنحو 10,1 مليون فدان، وهذا الأمر يوضح أهمية مساهمة النباتات الطبية و العطرية في زيادة قيمة الصادر ات الزر اعية المصرية وضرورة التوسع في زر اعتها لتعظيم قيمة هذه الصادر ات(؟). كما تعتبر محافظات شمال الصعيد (الفيوم بني سويف - المنيا - أسيوط) من أهم المحافظات المنتجة للنباتات الطبيـــة و العطريــة، حيـــث تتوفر الظروف الملائمة للإنتاج، و الميزة النسبية العالية من حيث الكمية و الجودة وتعدد أنو اعها،

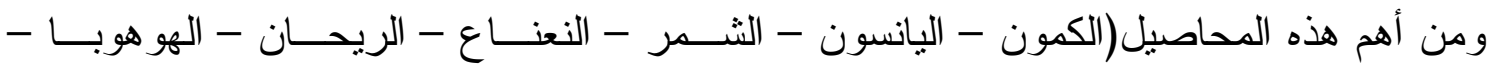

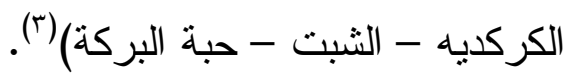

Received on: $13 / 12 / 2014$ Accepted for publication on: $31 / 1 / 2015$

Referees: Prof. Mohamed A. Abo-Nahoul Prof. Mohamed A. Kamel (1) ياسر حامدي عبد اللاه علي ، در اسة تحليلية للتجارة الخارجية المصرية لأهم الزرورع الطبية و العطرية، رسالة دكتــور اه ، قســـ

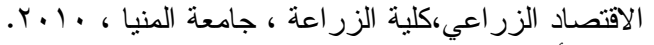

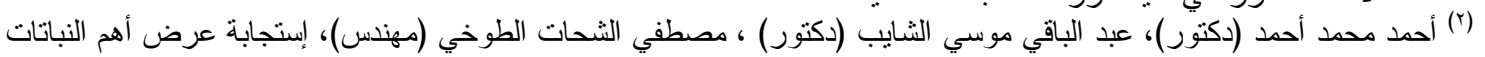

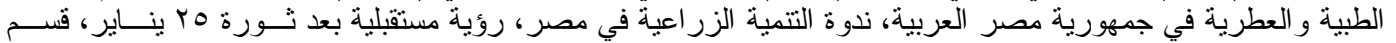

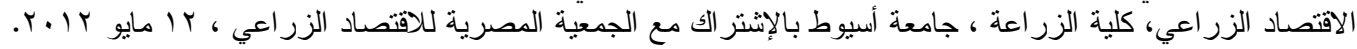

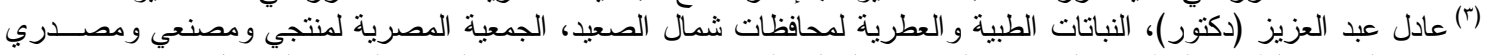

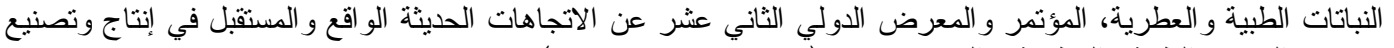

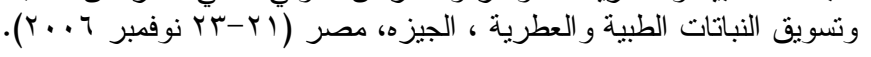


مشكلة البحث و أهدافه:

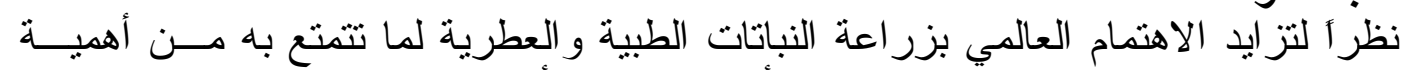

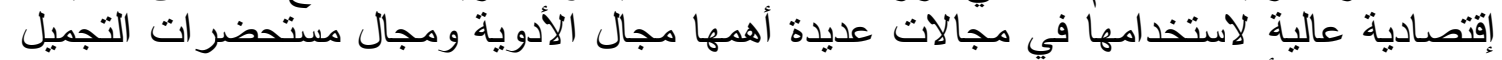

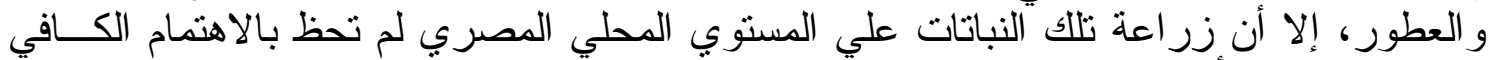

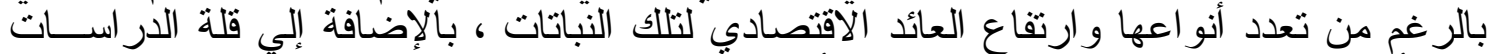

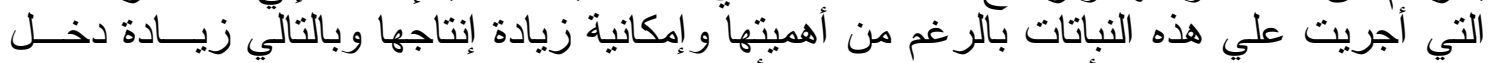

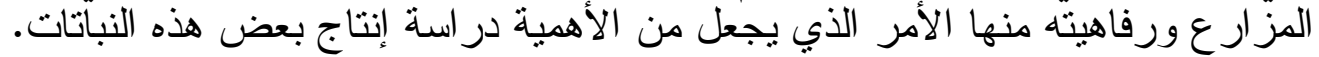

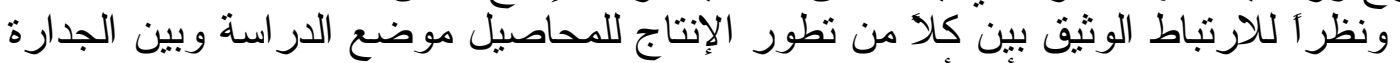

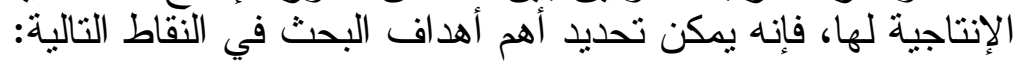

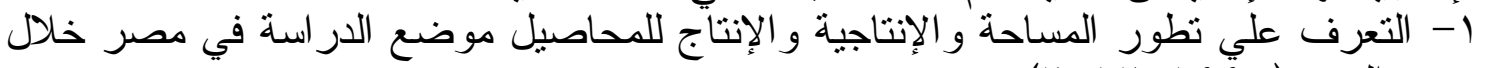

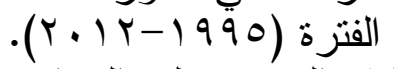

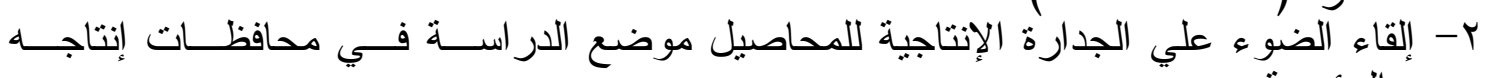
الرئيسية.

r- إلقاء الضّوء علي الجدارة الإنتاجية للمحاصيل موضع الدر اسة في مر اكز إنتاجها الرئيسـبة بمحافظة أسيوطً. الأسلوب البحثي ومصادر البيانات:

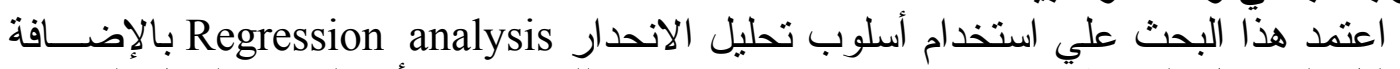

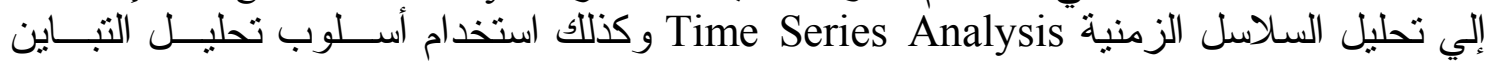

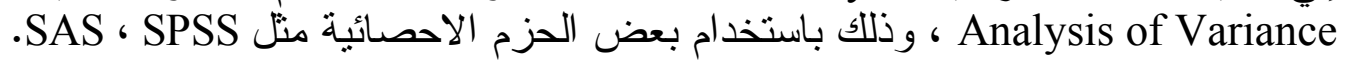

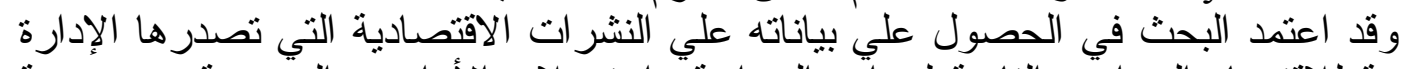

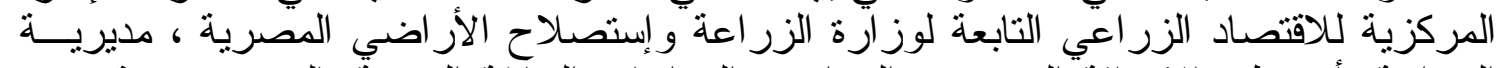

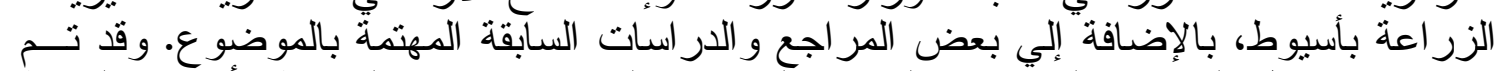

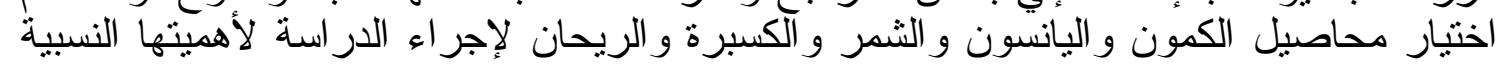

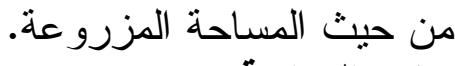
نتائج الدر استة: انتهت الدر اسة إلي العديد من النتائج و التي ترتبط بالجو انب التالية:

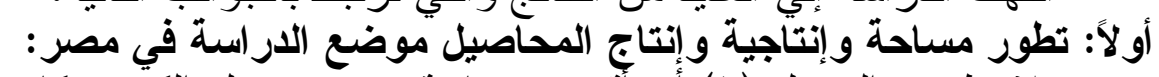

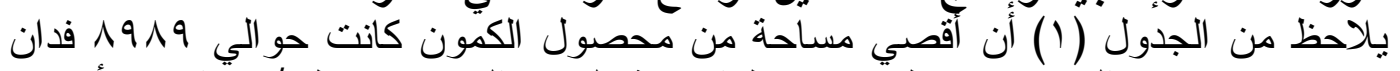

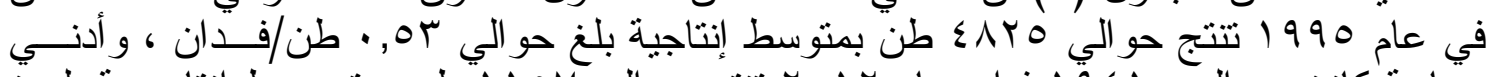

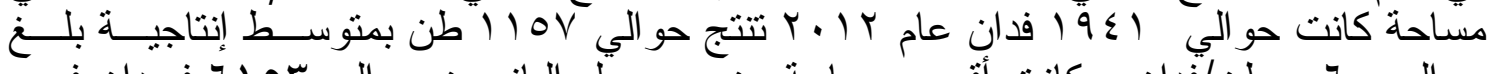

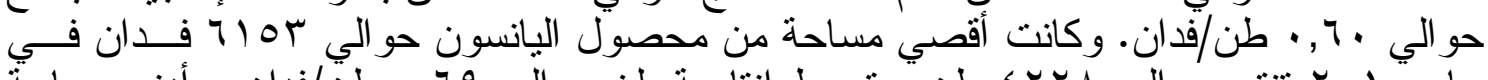

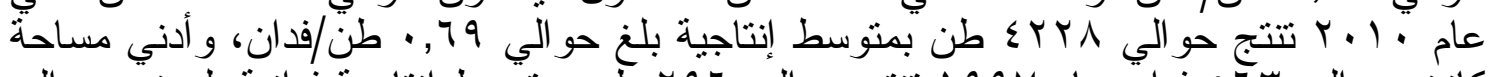

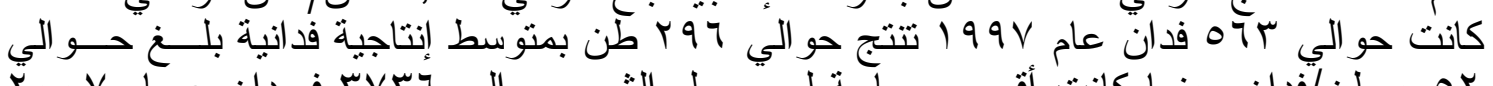

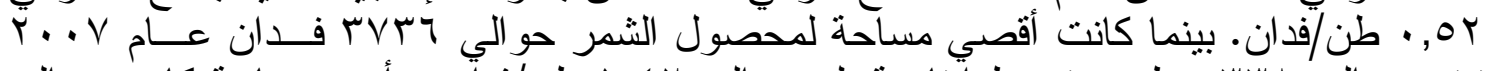

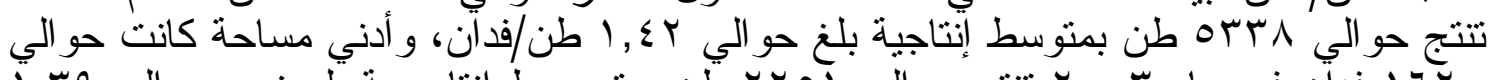

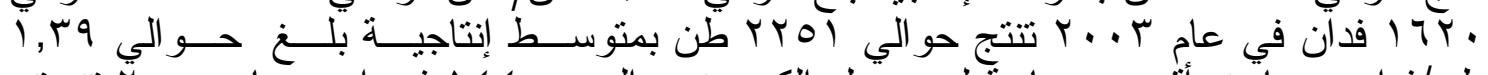

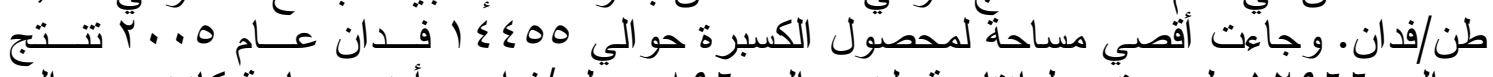

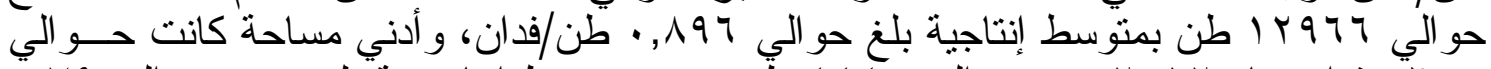

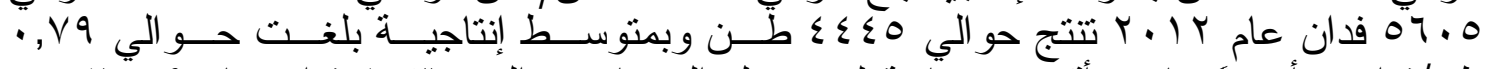

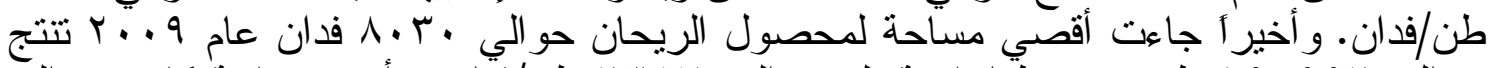

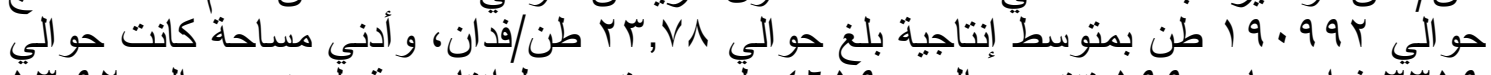

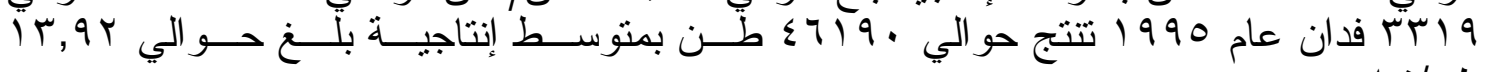

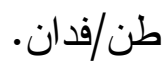

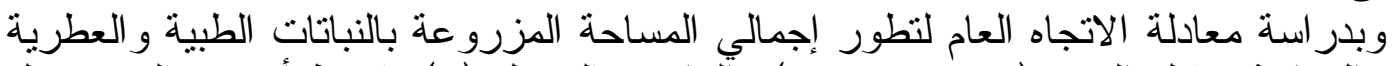

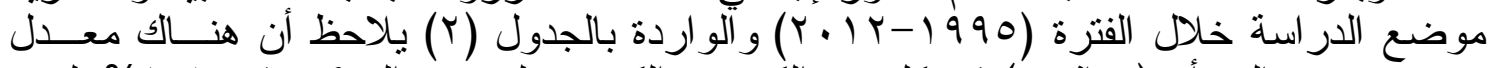

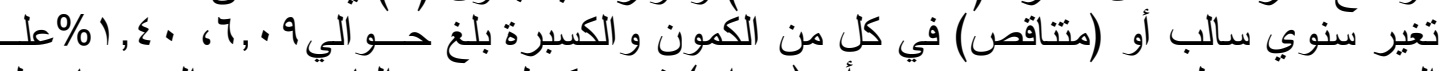

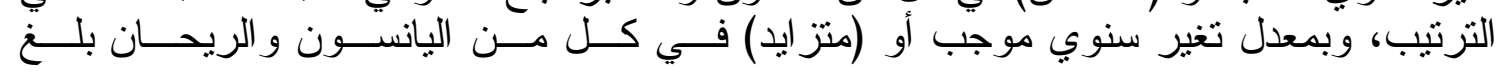




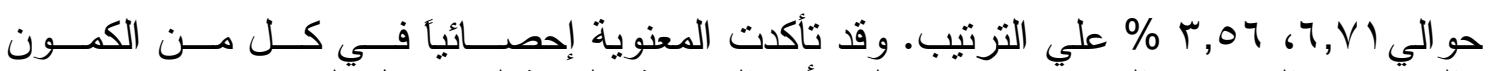
و اليانسون و الكسبرة و الريحآن في حين لم تتاكد المعنوية بالنسبة لمحصول الثئمر . 
جدول (1): تطور المساحة والإنتاجية والإنتاج للمحاصيل موضع الار اسة فـي مصـر خــلال

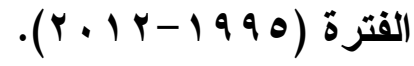

\begin{tabular}{|c|c|c|c|c|c|c|c|c|c|c|c|c|c|c|c|}
\hline \multicolumn{3}{|c|}{ الريحان } & \multicolumn{3}{|c|}{ الكسبرة } & \multicolumn{3}{|c|}{ الشمر } & \multicolumn{3}{|c|}{ الياتسون } & \multicolumn{3}{|c|}{ الكمون } & \multirow{2}{*}{ المحصول } \\
\hline طالإتـاج & |طن/فأانية & |المساحة & طالإنتاج & طن/فإنان & فالمساحة & $\mid$\begin{tabular}{|c|} 
طإنتاج \\
\end{tabular} & |طن/فإنية & فالمساحة & طن الإنتاج & |طن/فاجية & |المسانة & طن & & |لمدان & \\
\hline$\sum 719$. & & 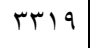 & $7 \leqslant 17$ & , $९ 9$ & אזיט & r. & I,AY & $19 \%$. & $\{71$ & 01 & $\wedge \wedge \wedge$ & \&AYO & & 19८9 & 1990 \\
\hline 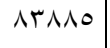 & & & 11. & & 711 & 179 & rV & 99 & 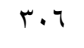 & & & OrN & & VTI & 99 \\
\hline $71 \Upsilon 97$ & & 991 & 91. & 997 & $9 \leq 7$ & 107 & , IV & $T \leq 4$ & 97 & & & VV & & & \\
\hline rorE. & & irv & 074 & 994 & $4 \wedge 7$ & $r v$ &, 11 & $7 \leqslant 0$ & $\mathrm{Vq}$ & $\cdot, \leqslant 7$ & To0 & $47 \varepsilon$ & & $0 .$. & 99 \\
\hline ז. & & rutv. & Or人 & $\cdot, 90$ & rAl &.$r$. & $\cdot, \mathrm{V}$ & vo. & 099 & $\cdot, \Sigma V$ & ro. & 090 & & $\varepsilon V T$ & \\
\hline & & & . & $\cdot, 9 \Gamma \wedge$ & & 190 & $r$ & & 7. & $\cdot, \leqslant 9$ & $00 \leqslant$ & rvo & & $T V$ & . \\
\hline & & & irv & $\cdot, q \sqcap q$ & & 74 & $r$ & $\leqslant v$ & & $\cdot, 0 \leq$ & & Tr. &,$\leqslant 0$ & . 49 & . \\
\hline & & & & $\cdot, \vee \circ$. & & $\leqslant r$. & $\varepsilon$ & & & $\cdot, 01$ & & AN &,$\leqslant \Lambda$ & $11 \mathrm{~V}$ & .. \\
\hline & $4, \cdot 7$ & & $(\cdot v$ & $\cdot, \vee \vee \neg$. & & 01 & & . & & ,or & & & & & $r \ldots$ \\
\hline & 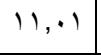 & $\varepsilon \cdot r q$ & & , ८ १ & & V.O & . & & & $\cdot, 01$ & & & & & 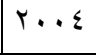 \\
\hline & & & & ,А97 & & $-9 \leqslant$ & & & & $\cdot, 09$ & & & & & 18 \\
\hline & & & & $9 \cdot 1$ & & «०V & & & & $\cdot, 0 \mathrm{~V}$ & & & & $V V Y$ & 18 \\
\hline & $0, \wedge 1$ & & & 91. & $\leqslant \leqslant \leqslant$ & rra & & & & $\cdot, 09$ & & $r 7.1$ & & & . \\
\hline & $\varepsilon, \wedge \wedge$ & $\Sigma \vee \wedge$. & & $\cdot, q \cdot r$ & $\Lambda . \vee q$ & $9 \vee \leqslant$ & & & & & & ITHN & & & . \\
\hline 19.994 & $r r, r \wedge$ & $\Lambda \cdot r \cdot$ & $17 \varepsilon$ & $\cdot, 99$. & .194 & rrt. & & $r \cdot \Lambda$. & 1. & & $19 \varepsilon$. & 1890 & & T107 & 1.0 \\
\hline $101 \ldots$ & & ס דזד & Avo & & १९४ & $r V \leqslant \Lambda$ & $1, \cdot 2$ & TV & & & & 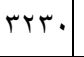 & $\cdot, 09$ & $0 \leq \leqslant 1$ & \\
\hline & Y), vo & & & & & rAv & & $r 9.7$ & 1211 & $\cdot, 79$ & & rITr & & $r \leqslant \wedge q$ & $r \cdot 1$ \\
\hline & & & & & & root & & & & $\cdot,\rceil \varepsilon$ & & $110 \mathrm{~V}$ & $\cdot, 7$ & $19 \leqslant 1$ & $r .1 T$ \\
\hline & 18,04 & & 719 & - ،VAr & 178. & $1 \leq$. & & & & ., OV & & rAVY & , OY & $04 \leqslant 9$ & \\
\hline
\end{tabular}

المصدر: وزارة الزر اعة و إستصلاح الأراضي ، الإدارة المركزية للاقتصـاد الزر اعـي، نشــرة الإحصــاءات

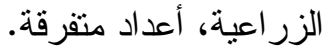

جدول (Y): معادلات الاتجاه العام لتطور إجمالي المساحة المزروعة للمحاصيل موضع الدراسة

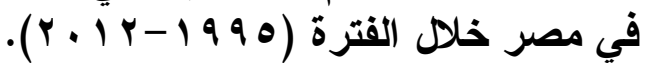

\begin{tabular}{|c|c|c|c|c|c|c|c|}
\hline $\begin{array}{c}\% \\
\text { السنغيري } \\
\end{array}$ & متوسط & التغنير & ف & ر & J & المعادلة & المحصول \\
\hline $7, \cdot 9-$ & $07 \leq 9$ & $r \leqslant \varepsilon, r_{O}-$ & $* * ץ 9,00$ & $\cdot, 7 \leq 9$ & $\cdot, 1 \cdot 0$ & 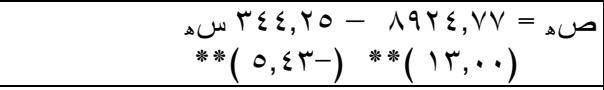 & الكمون \\
\hline $7, \times 1$ & 1977 & $1 T 1,9 V$ & $* 0,97$ & $\cdot, Y V I$ & $\cdot, 0 Y 1$ & 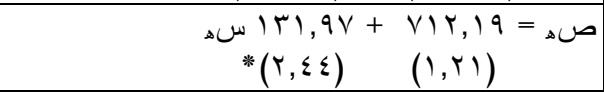 & الياتسون \\
\hline - & - & - & $r, I V$ & $\cdot, 119$ & $\cdot r \leq 7$ & $\begin{array}{c}\Delta \omega r \Sigma, r)+r \cdot q \Lambda, r q=\Delta \Delta \\
(1, \Sigma V) * *(\wedge, r r)\end{array}$ & الثمر \\
\hline $1, \varepsilon \cdot-$ & 1178. & וד,10- & $* 0, r V$ & $\cdot, \Sigma \backslash \vee$ & $\cdot, 7 \leq 7$ & 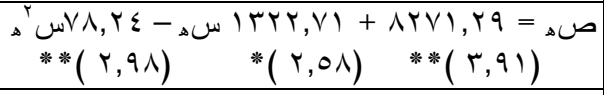 & الكسبرة \\
\hline$r, 07$ & $\varepsilon 9 \pi \wedge$ & $1 \vee V, 1 T$ & $* * 10,1 \mathrm{~V}$ & $\cdot, \varepsilon \wedge \vee$ & $\cdot, 79 \wedge$ & 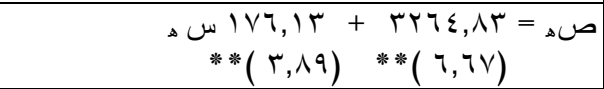 & الريحان \\
\hline
\end{tabular}

المصدر: حسبت من جدول (1). 


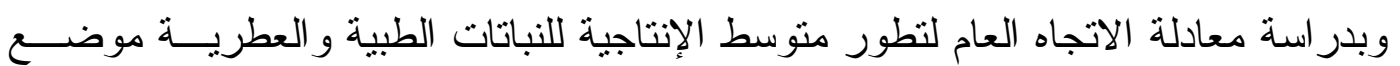

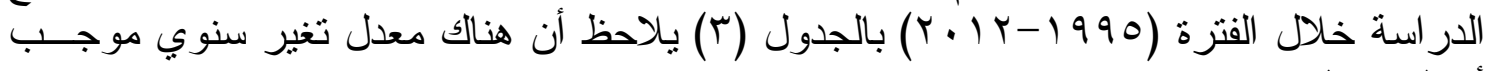

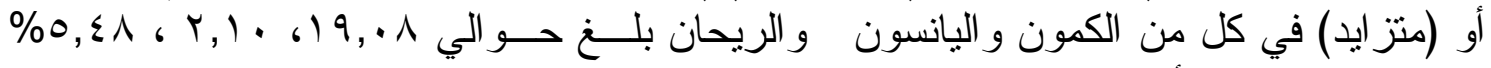

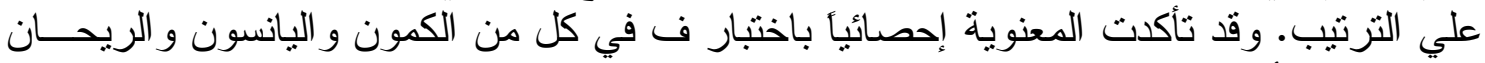
في حين لم تتأكد معنوية الثمر و الكسبرة.

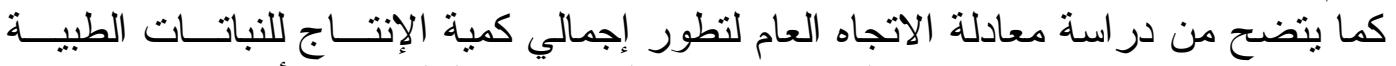

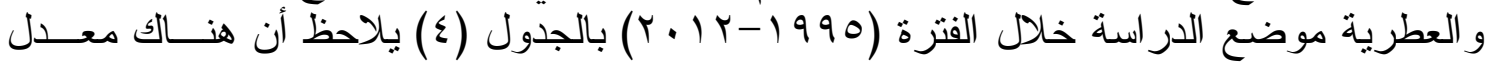

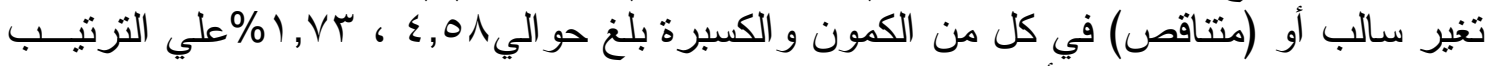

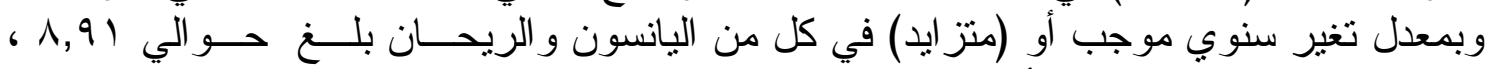

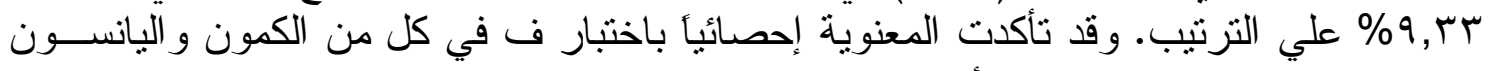
و الكسبرة و الريحان في حين لم تثتأكد معنوية الثمر .

جدول (ץ): معادلات الاتجاه العام لتطور متوسط إنتاج الفدان للمحاصيل موضع الار اســـة فــي

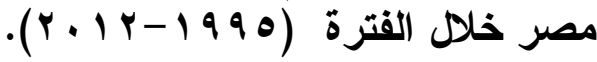

\begin{tabular}{|c|c|c|c|c|c|c|c|}
\hline التنغير & الظتوسط & التنغير & ف & נر & J & المعادلة & المحصول \\
\hline $19, \cdot 1$ &., $0 Y \varepsilon$ & $\cdot, 1$. & ד & • & r, & 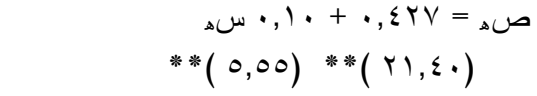 & الكمون \\
\hline$r, 1$. & $\cdot$, OV & $\cdot, \cdot, T$ & ס ד, & - $\vee \vee 99$ & $\cdot, \wedge 9 \leqslant$ & 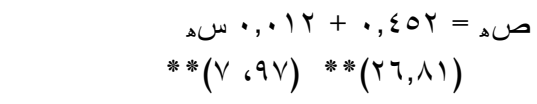 & الياتسون \\
\hline- & - & - & .,.9Y & $\cdot, \ldots 7$ & $\cdot, \cdot \vee V 4$ & 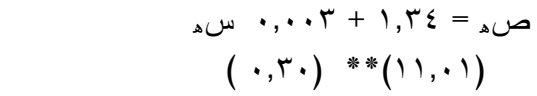 & الثُمر \\
\hline- & - & - & $1, r)$ & $\cdot, \cdot V 4$ & , YVY & 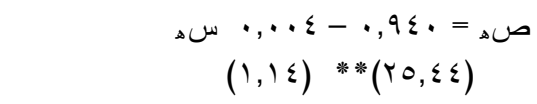 & الكسبرة \\
\hline $0, \Sigma \wedge$ & $1\{, 09$ & $\cdot, \wedge$. & $* * q, 1 \leq$ & $\cdot, 0 \leqslant 9$ & $\cdot, v \varepsilon 1$ & 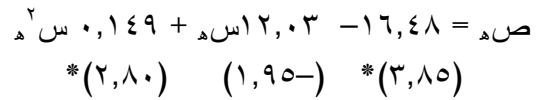 & الريحان \\
\hline
\end{tabular}

المصدر: حسبت من جدول (1) (1)

جدول (ء): معادلات الاتجاه العام لتطور إجمالي كمية إنتاج المحاصيل موضع الدراســـة فـي

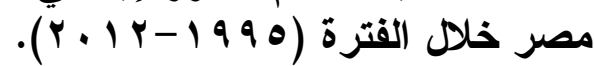

\begin{tabular}{|c|c|c|c|c|c|c|c|}
\hline 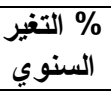 & الظتوسط & | السنوي & ف & נر & J & المعادلة & المحصول | \\
\hline$\varepsilon, 0 \wedge-$ & YAVT & $|r|, V \varepsilon-$ & $* * 1, Y, 9 \Lambda$ & $\cdot$, . $\leqslant$ « & . & 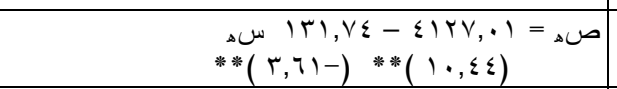 & الكمون \\
\hline$\wedge, 9)$ & $11 \mathrm{VI}$ & $1 \cdot \Sigma, \Gamma 4$ & $* \wedge, 7)$ & . Tro. & . & 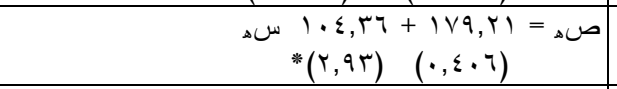 & اليانسون \\
\hline- & - & - & $1, r$. & $\cdot, \cdot v_{0}$ & $\cdot, Y V \varepsilon$ & 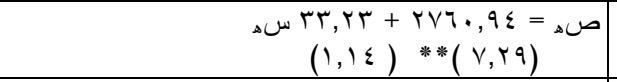 & الثمر \\
\hline $1, V r-$ & .719 & $\mid \wedge \varepsilon, T r-$ & *T,r & $\cdot, r \cdot \lambda$ & $\cdot, 000$ & 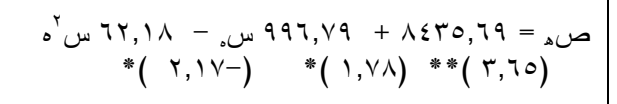 & الكسبرة \\
\hline $9, \pi r$ & VAYVE & $V T \cdot \varepsilon, \cdot T$ & $* * 10,7 \mathrm{~V}$ & $\cdot, 7 \vee 4$ & • AYr & 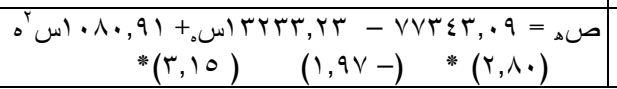 & الريحان \\
\hline
\end{tabular}




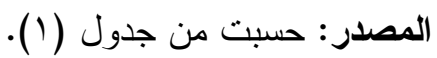
ثنانياً: الجدارة الإنتاجية للمحاصيل موضع الإن الإسة في مصر: 1 - الجدارة الإنتاجية لمحصول الإنية لإنمون في محافظات إنتاجه الرئيسية:

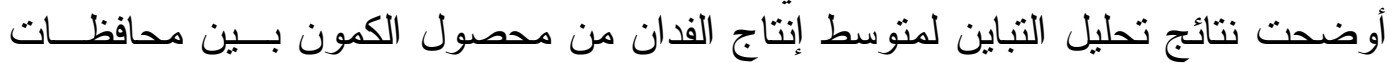

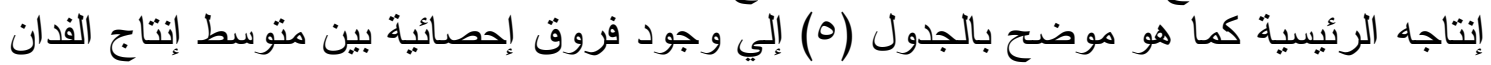

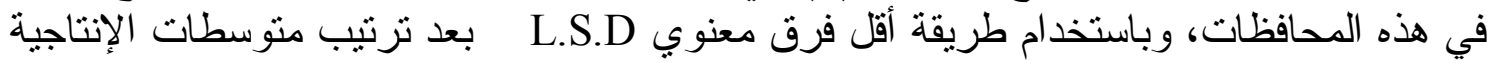

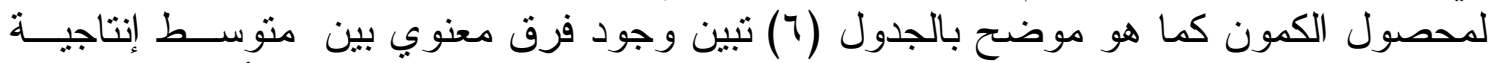

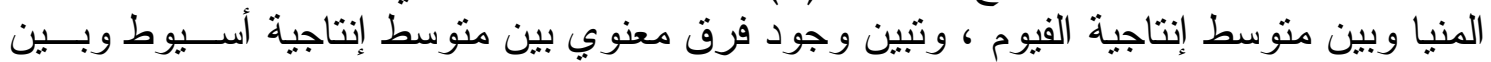

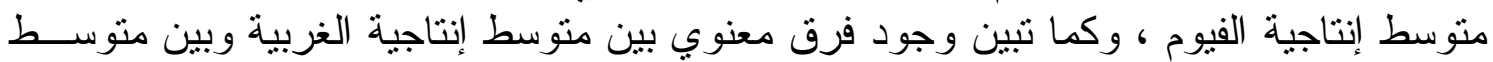

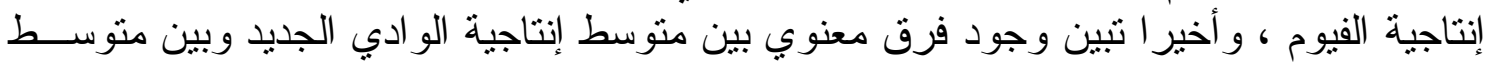

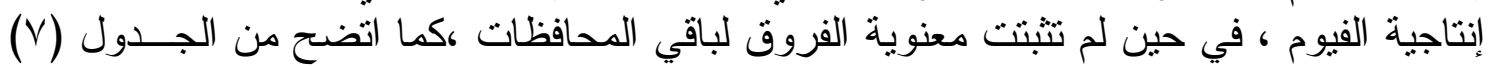

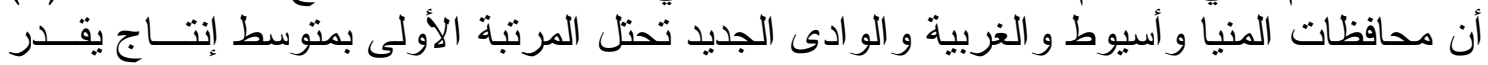

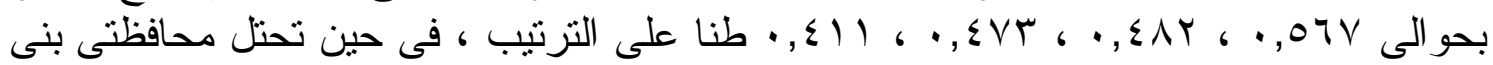

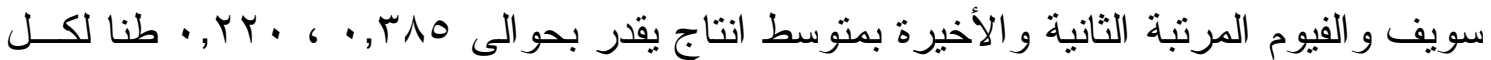
منهما على الترنيب.

جدول (0): نتائج تحليل التباين لمتوسط إنتاج الفدان بين المحافظات الرئيسية المنتجة للكمون

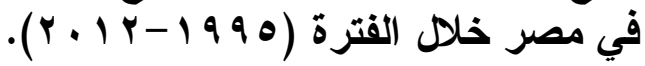

\begin{tabular}{|c|c|c|c|c|}
\hline نسبة التباين & مربعات الانحر مجوع & مجموع مربعات & (درجة الحرية) & مصدر الاختلاف \\
\hline \multirow[t]{2}{*}{$* r, q}$. & $\begin{array}{l}\cdot, Y \leq V \\
\cdot, \cdot 10\end{array}$ & $\begin{array}{l}1, r \times 4 \\
1,799\end{array}$ & $\begin{array}{c}0 \\
1 . r\end{array}$ & داخل المحافظات المحافظات \\
\hline & • & $9,9 \times 0$ & $1 . v$ & المجموع \\
\hline
\end{tabular}

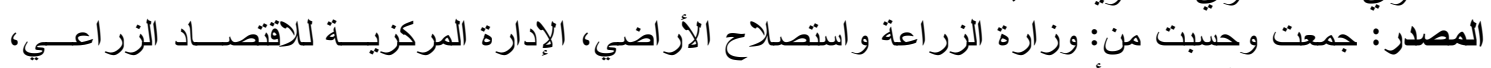

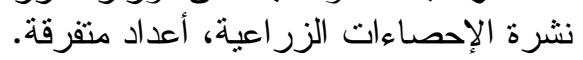

جدول (7): تحليل (أقل فرق معنوي) لبيانـات متوسط إنتاج الفدان لأهم المحافظــات المنتجــة لمحصول الكمون.

\begin{tabular}{|c|c|c|c|c|c|c|}
\hline المنيا & أسيوط & الغربية & الوادي الجديد & بني سويف & الفيوم & المحافظة \\
\hline- & $\cdot, \wedge \varepsilon$ &., .94 &., 100 & $\cdot,|\wedge|$ & $* *, r \leq \varepsilon$ & المنيا \\
\hline- & - & $\cdot, \cdots 9$ & $\cdot, \cdot V_{1}$ &., $.9 V$ & *.,YY. & أسيوط \\
\hline- & - & - & $\cdot, \cdot 71$ & $\cdot, \cdot \Lambda V$ & *., YO. & الغربية \\
\hline- & - & - & - & $\cdot$, Y YO & $*, 1 \wedge 9$ & الو ادى الجديد \\
\hline- & - & - & - & - & מדות & بني سويف \\
\hline- & - & - & - & - & - & الفيوم \\
\hline
\end{tabular}

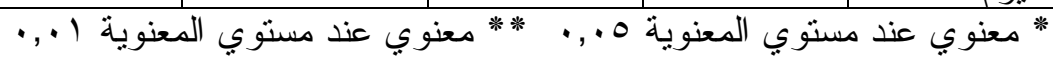

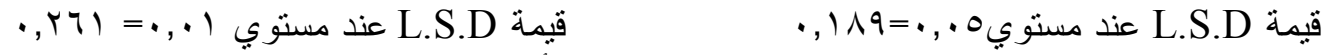

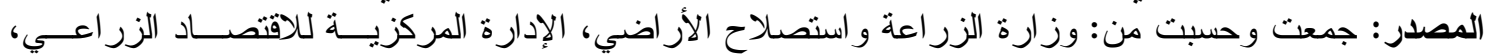

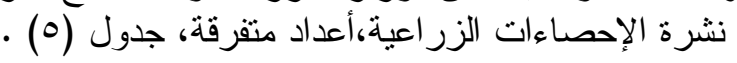


جدول (V): نتائج تحليل أقل فرق معنوي لترتيب المحافظات الرئيسية المنتجة للكمــون وفة أنــاً

\begin{tabular}{|c|c|c|}
\hline الترتيب & متوسط إنتاج الفدان بالطن & المحافظة \\
\hline 1 & $\cdot, 07 \mathrm{~V}$ & المنيا \\
\hline 1 & $\cdot, \varepsilon \wedge r$ & 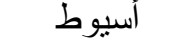 \\
\hline 1 & $\cdot, \Sigma \vee T$ & الغربية \\
\hline 1 & $\cdot, \varepsilon 引$ & الو ادي الجديد \\
\hline$r$ & $\cdot, \Gamma \wedge 0$ & بني سويف \\
\hline r & $\cdot$, YT. & 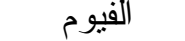 \\
\hline
\end{tabular}

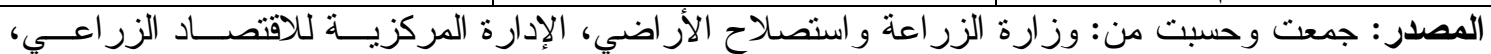

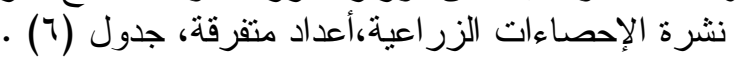

r- الجدارة الإنتاجية لمحصول اليانسون في محافظات إنتاجه الرئيسية:

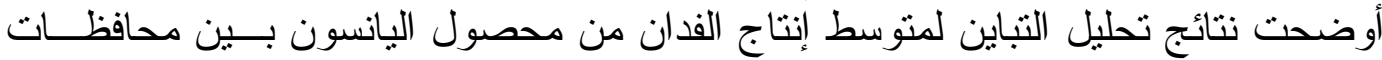
إنتاجه الرئيسية كما هو موضح بالجدول (^) إلي وجود فروق فون مؤكدة إحصائياً بين متوسط إنتاج

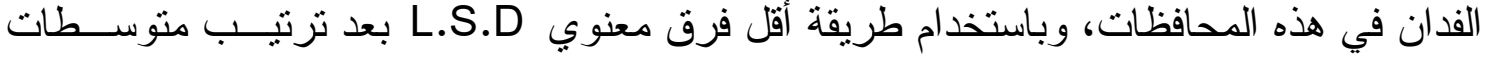

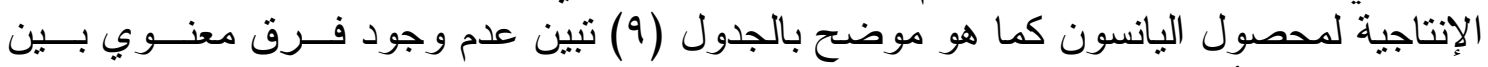

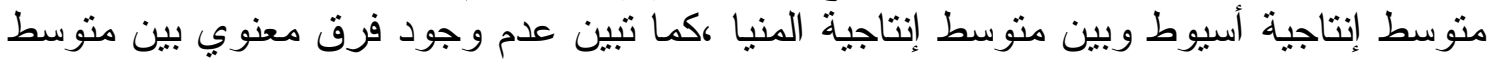

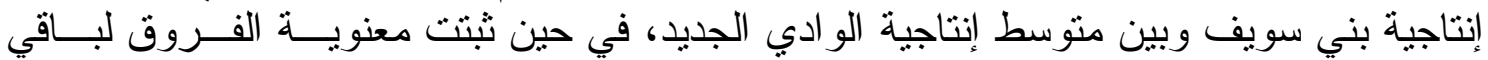

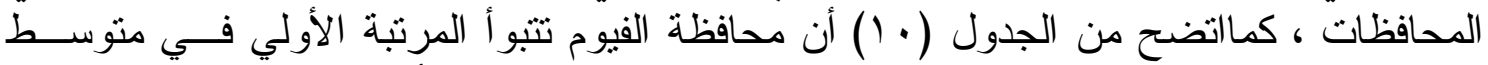

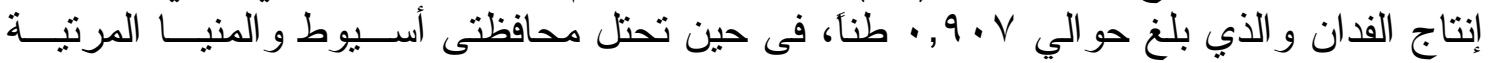

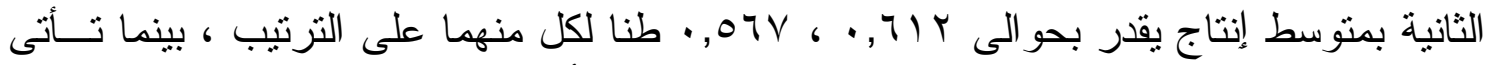

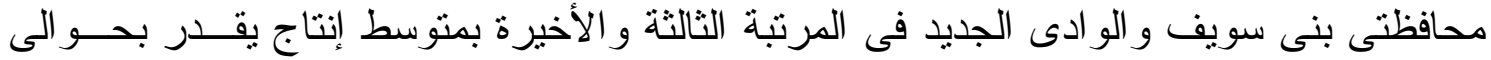

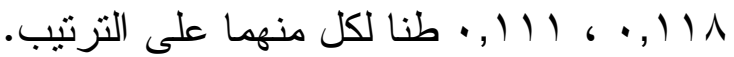

جدول (^): نتائج تحليل التباين لمتوسط إنتاج الفدان بـين المحافظــات الرئيسـية المنتجــة

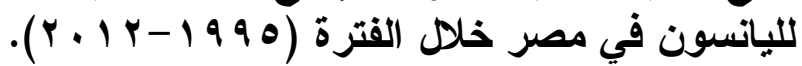

\begin{tabular}{|c|c|c|c|c|}
\hline نسبة التباين & مربعات الانحر مجموع & مجموع مربعات & درجة الحرية & مصدر الاختلاف \\
\hline \multirow{3}{*}{$* * \varepsilon r, \wedge \leqslant$} & $r, 1 r q$ & $\wedge, 017$ & $\varepsilon$ & بين المحافظات \\
\hline & $\cdot, \cdot \leq 9$ & E,YYT & 10 & داخل المحافظات \\
\hline & $r, I V \wedge$ & Ir,Vrq & 19 & المجموع \\
\hline
\end{tabular}

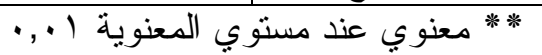

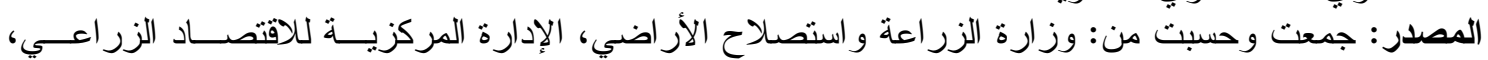
نشرة الإحصاءات الزر اعبة، أعداد متفرقة.

جدول (9): تحليل (أقل فرق معنوي) لبيانـات متوسط إنتاج الفدان لأهم المحافظــات المنتجــة لمحصول الياتسون.

\begin{tabular}{|c|c|c|c|c|c|}
\hline الفيوم & أسيوط & المنيا & بني سويف & الوادي الجديد & المحافظة \\
\hline- & $* *, Y q \leq$ & ***,,$\Gamma \leq$. & $* *, \vee \vee \wedge \wedge$ & $* *, \vee \vee 97$ & الفيوم \\
\hline- & - & $\cdot, \cdot \leqslant 0$ & $* *,, \leq 9 \leq$ & $* * \cdot, 0,1$ & أسيوط \\
\hline- & - & - & $* *,, \leqslant \leqslant \wedge$ & $* *,, \leq 00$ & المنيا \\
\hline- & - & - & - & $\cdot, \cdots v$ & بني سويف \\
\hline- & - & - & - & - & الو ادي الجديد \\
\hline
\end{tabular}




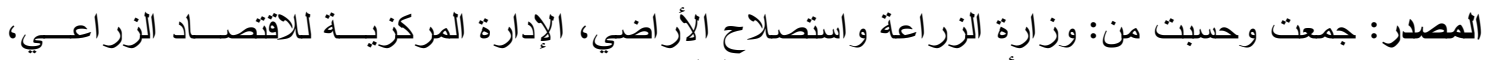

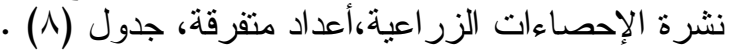

جدول ( • (): نتائج تحليل أقل فرق معنوي لترتيب المحافظات الرئيسية المنتجة لليانسون وفقاً

\begin{tabular}{|c|c|c|}
\hline الترتيب & متوسط إنتاج الفدان بالطن & المحافظة \\
\hline 1 & $\cdot, 9 \cdot \mathrm{V}$ & الفيوم \\
\hline$r$ & $\cdot, T / Y$ & أسيوط \\
\hline$r$ & $\cdot, 07 \mathrm{~V}$ & المنيا \\
\hline r & $\cdot, 111$ & بني سويف \\
\hline$r$ & $\cdot, 111$ & الو ادى الجديد \\
\hline
\end{tabular}

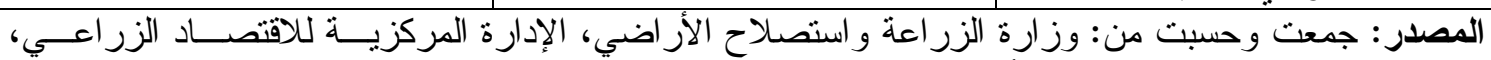

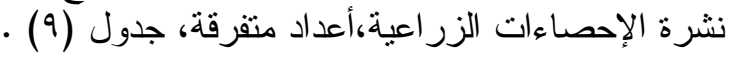

ب - الجدارة الإنتاجية لمحصول الشمر في محافظات إنتاجه الرئيسية:

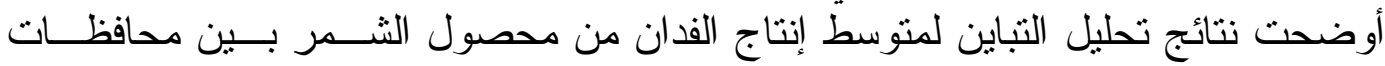

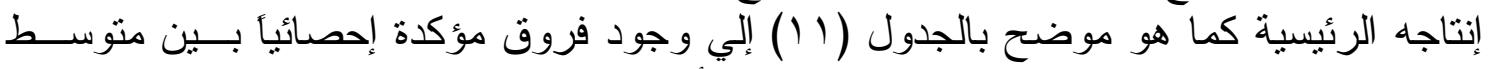

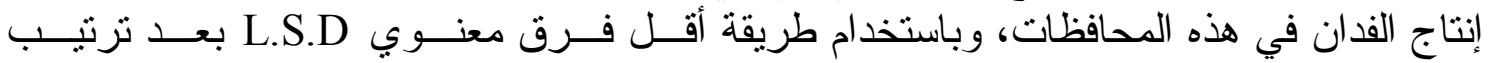

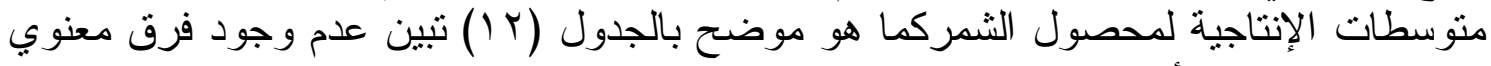

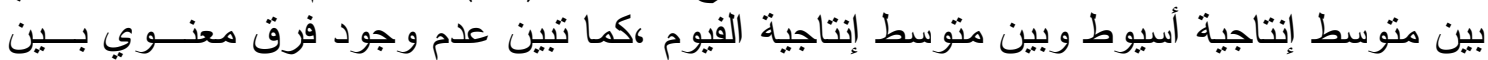

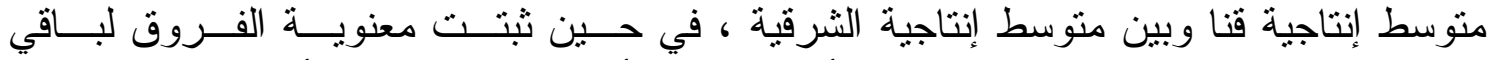

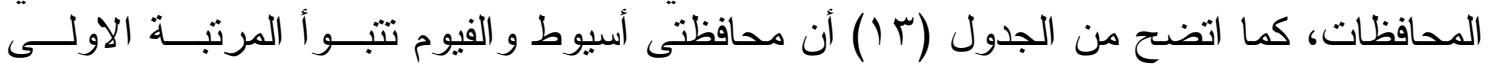

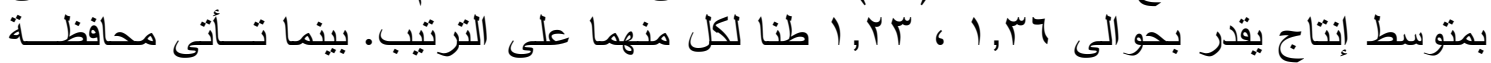

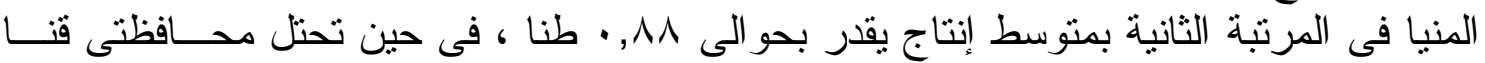

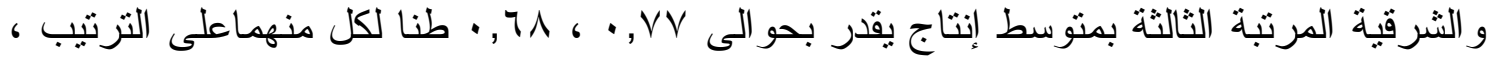

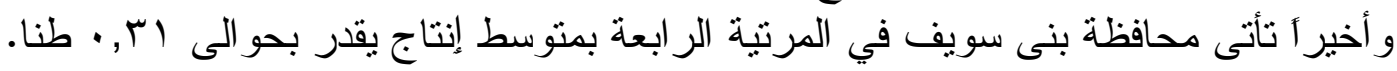

جدول (1 1): نتائج تحليل التباين لمتوسط إنتاج الفدان بين المحافظــات الرئيسـية المنتجـــة

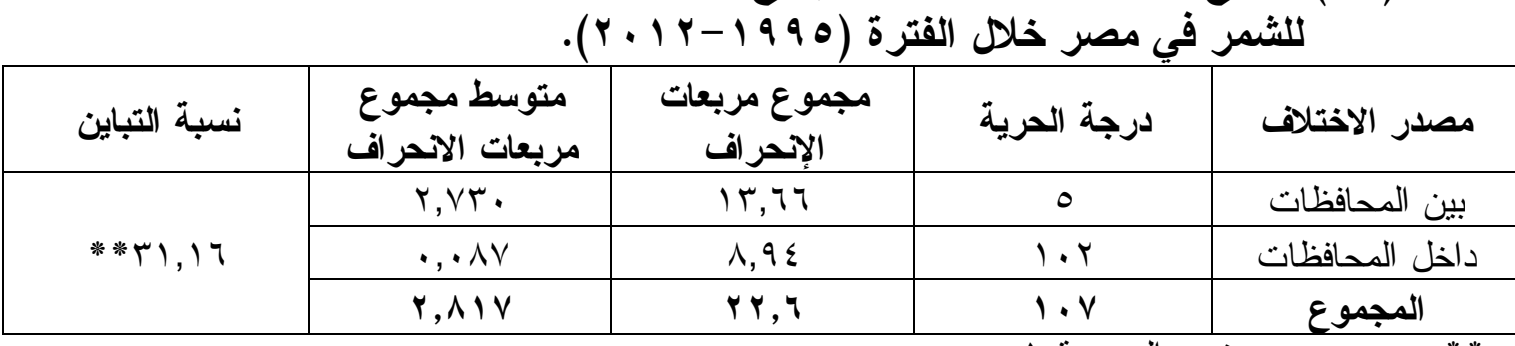

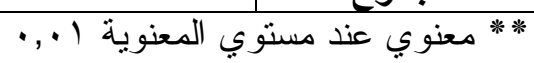

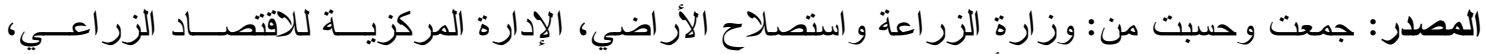

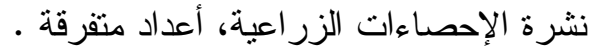

جدول (Y I): تحليل (أقل فرق معنوي) لبيانات متوسط إنتاج الفدان لأهم المحافظات المنتجــة

\begin{tabular}{|c|c|c|c|c|c|c|}
\hline & & & & \multicolumn{3}{|c|}{ لمحصول الشمر. } \\
\hline أسيوط & الفيوم & المنيا & قنا & الشرقية & بني سويف & المحافظة \\
\hline- & $\cdot, I T r$ & $* *,, \leqslant \vee q$ & $* *, 09$. & $* *,, T \wedge r$ & $* * 1, .0$ & أسيوط \\
\hline- & - & $* *, \Gamma \leq \nearrow$ & $* *,, 0 \leq 9$ & $*,, 0 \leqslant \Lambda$ & **, , 9YY & الفيوم \\
\hline- & - & - & $* \cdot, r \cdot r$ & $* \cdot, r \cdot I$ & $* *, 0 \vee 0$ & المنيا \\
\hline- & - & - & - & $\cdot, \ldots 1$ & $* *, r V r$ & قنا \\
\hline- & - & - & - & - & ***,rVY & الثرقية \\
\hline- & - & - & - & - & - & بني سويف \\
\hline
\end{tabular}

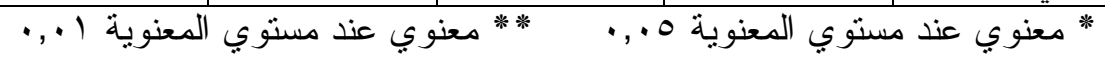




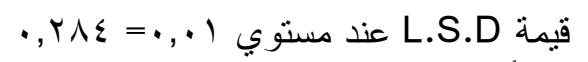

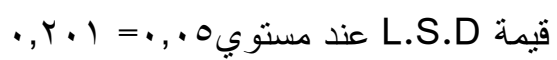

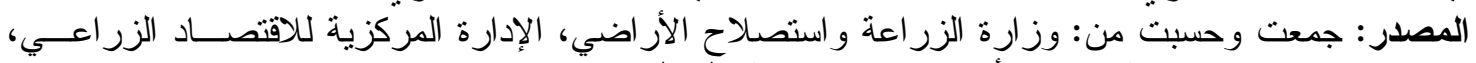

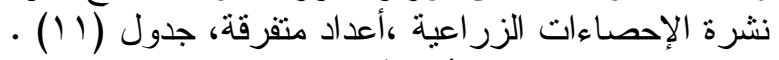

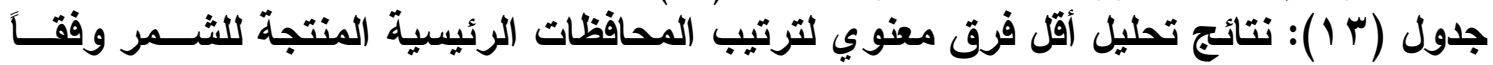

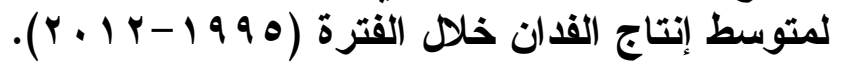

\begin{tabular}{|c|c|c|}
\hline الترتيب & متوسط إنتاج الفدان بالطن & المحافظة \\
\hline 1 & $1, r 4$ & أسيوط \\
\hline 1 & $1, r \pi$ & الفيوم \\
\hline r & $\cdot, \wedge \wedge$ & المنيا \\
\hline$r$ & $\cdot, V V$ & قنا \\
\hline$r$ & $\cdot, 71$ & الشرقية \\
\hline$\varepsilon$ & $\cdot, r$ & بني سويف \\
\hline
\end{tabular}

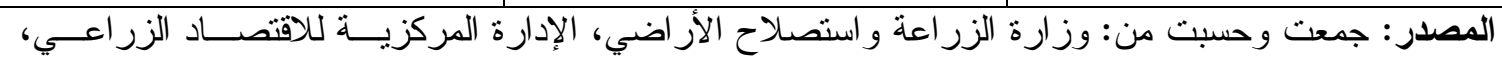

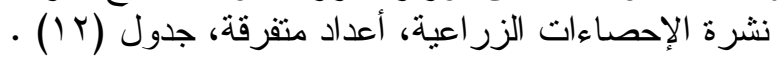

ع- الجدارة الإنتاجية لمحصول الكسبرة في محافظات إنتاجه الرئيسية:

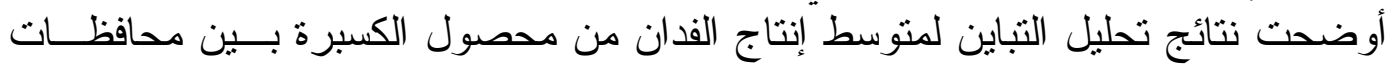

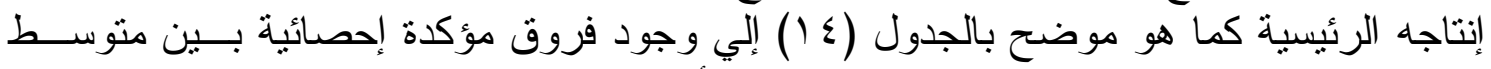

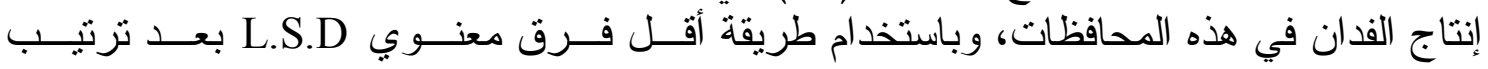

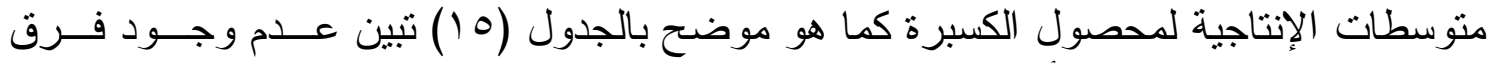

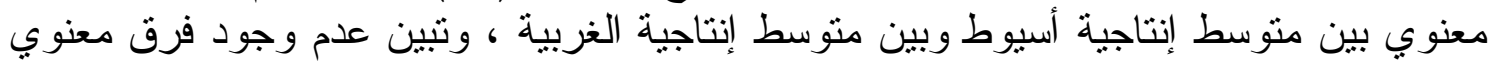

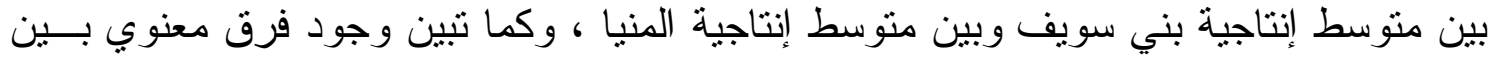

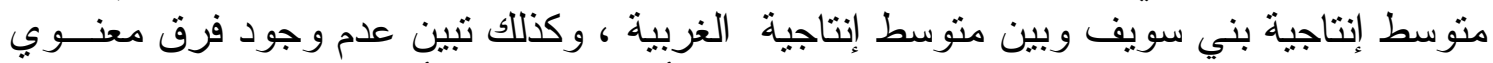

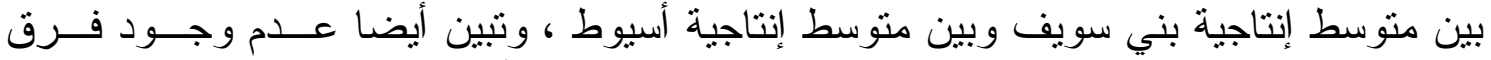

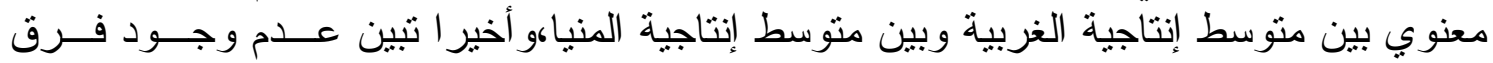

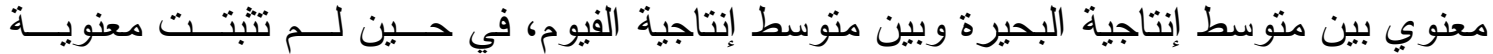

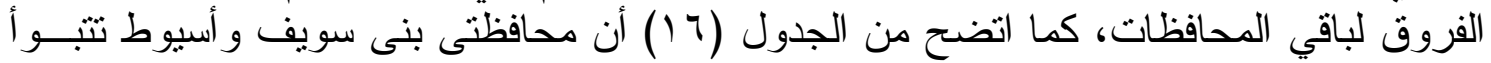

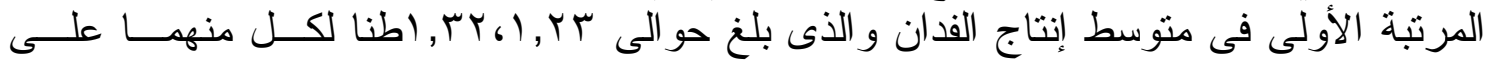

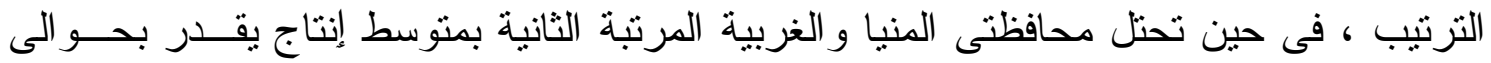

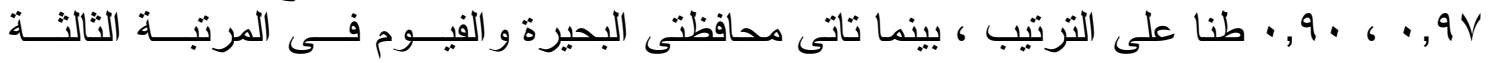

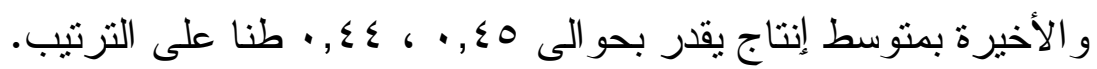

جدول (ع 1): نتائج تحليل التباين لمتوسط إنتاج الفدان بين المحافظــات الرئيسـية المنتجــة

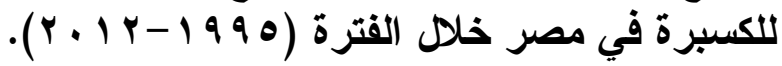

\begin{tabular}{|c|c|c|c|c|}
\hline نسبة التباين & 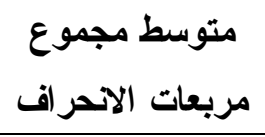 & مجموع مربعات & درجة الحرية & مصدر الاختلاف \\
\hline \multirow{3}{*}{$* * \mid 9, \varepsilon)$} & $r, 17 \varepsilon$ & $10, \lambda r$ & 0 & بين المحافظات \\
\hline & r & 17,01 & $1 \cdot r$ & داخل المحافظات \\
\hline & $r, r r V$ & $r r, \varepsilon$. & $1 \cdot v$ & المجموع \\
\hline
\end{tabular}

* معنوي عند مستوي المعنوية 0., م 


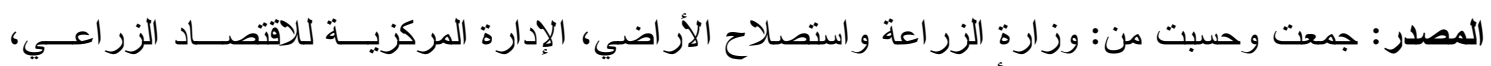

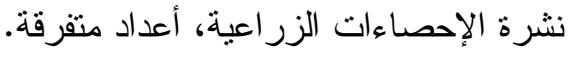


جدول (10): تحليل (أقل فرق معنوي) لبيانات متوسط إنتاج الفـان لأهم المحافظات المنتجــة

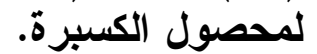

\begin{tabular}{|c|c|c|c|c|c|c|}
\hline أسيوط & بني سويف & الغربية & المنيا & البحيرة & الفيوم & المحافظة \\
\hline- & $\cdot, \cdot \vee 7$ & $\cdot, r \cdot q$ & $*, r \vee q$ & $* *, V Y T$ & $* *,, \vee \uparrow \wedge$ & أسيوط \\
\hline- & - & rTM & $\cdot, Y \cdot r$ & $* *,,\rceil \leq \nearrow$ & $* *,, 771$ & بني سويف \\
\hline- & - & - & $\cdot, \cdot v \cdot$ & $* *, 01\{$ & $* *$, o 9 & الغربية \\
\hline- & - & - & - & $* *, \cdot, \leqslant \leqslant \Gamma$ & $* *, ., 0 \bigcirc$ & المنيا \\
\hline- & - & - & - & - & $\cdot, \mid r \varepsilon$ & البحيرة \\
\hline- & - & - & - & - & - & الفيوم \\
\hline
\end{tabular}

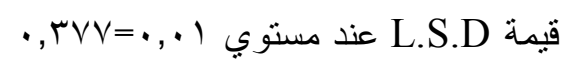

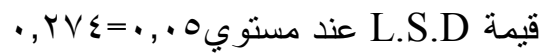

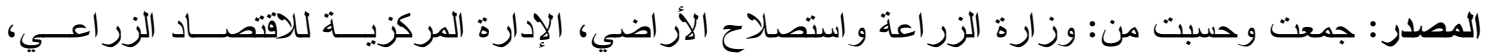

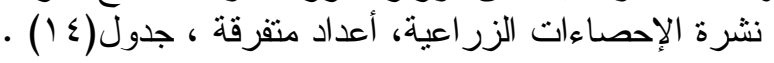

جدول (4 1 ): نتائج تحليل أقل فرق معنوي لترتيب المحافظات الرئيسية المنتجة للكسبرة وفقــاً

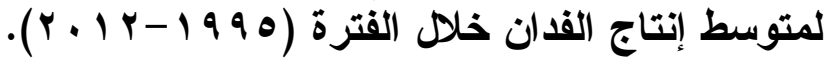

\begin{tabular}{|c|c|c|}
\hline الترتيب & متوسط إنتاج الفدان بالطن & المحافظة \\
\hline 1 & $1, r$, & أسيوط \\
\hline 1 & 1, r & بني سويف \\
\hline r & $\cdot, 9 \vee$ & الغربية \\
\hline r & $\cdot, 9$. & 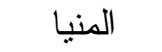 \\
\hline r & $\cdot, \leqslant 0$ & البحيرة \\
\hline$r$ & $\cdot, \leqslant \leqslant$ & الفيوم \\
\hline
\end{tabular}

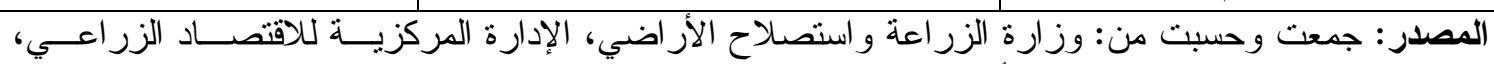
نشرة الإحصاءات الزر اعية، أعداد متفرقة، جدول (10)

ه- الجدارة الإنتاجية لمحصول الريحان في محافظات إنتاجه الرئيسية:

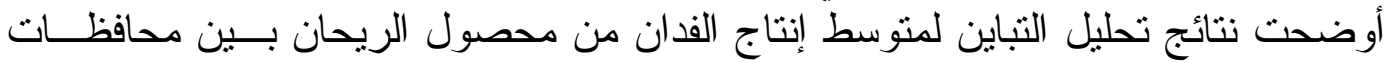

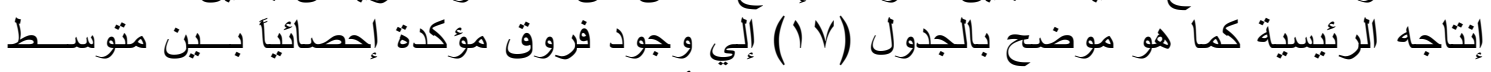

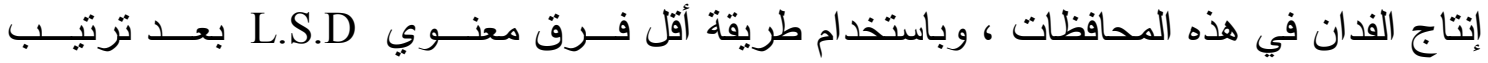

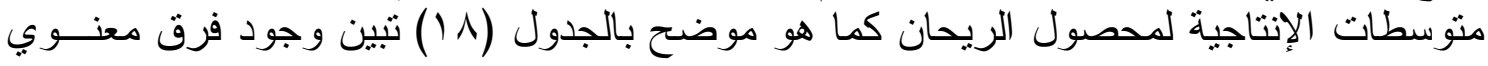

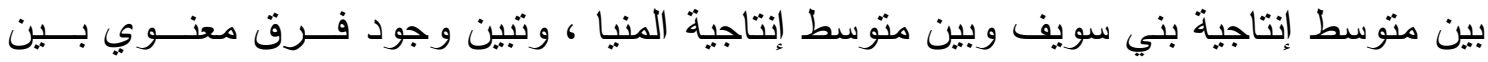

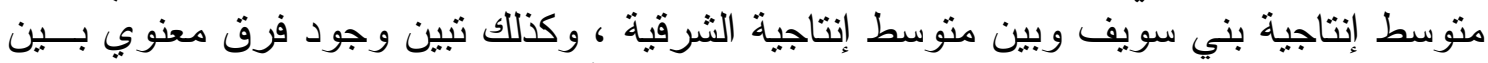

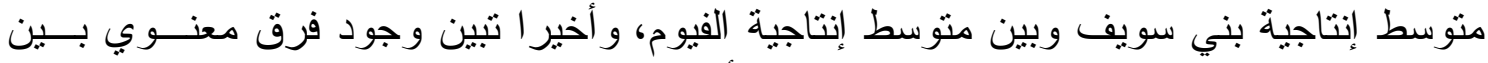

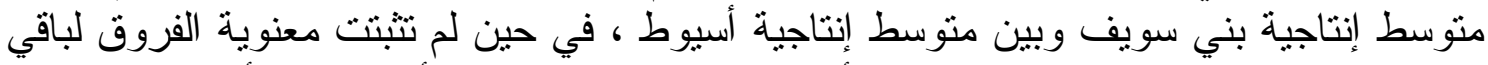

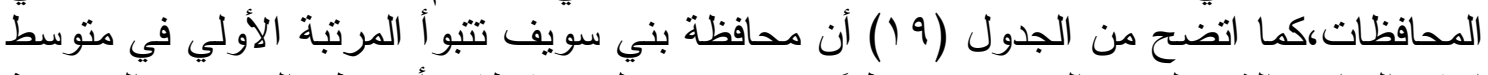

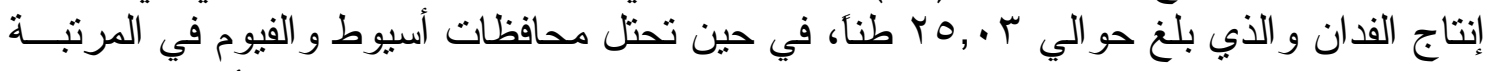

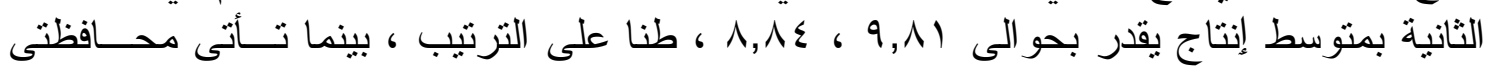

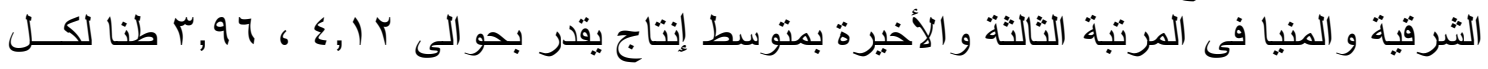

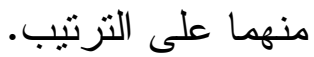


جدول ( V V): نتائج تحليل التباين لمتوسط إنتاج الفدان بين المحافظــات الرئيسـية المنتجــة

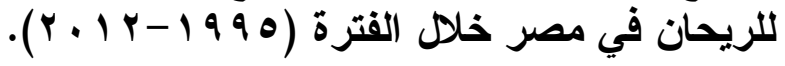

\begin{tabular}{|c|c|c|c|c|}
\hline نسبة التباين & متوسط مجموع & مجموع مربعات & درجة الحرية & مصدر الاختلاف \\
\hline \multirow{3}{*}{ **1 $9, \wedge r$} & $1 \varepsilon \cdot 1, r r$ & $07 \cdot\{, \wedge \Lambda$ & $\varepsilon$ & بين المحافظات \\
\hline & V., & r.r.,qr & 10 & داخل المحافظات \\
\hline & $1 \leqslant V 1, \wedge 0$ & $117 . \wedge, \wedge 1$ & $\wedge 9$ & المجموع \\
\hline
\end{tabular}

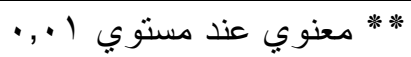

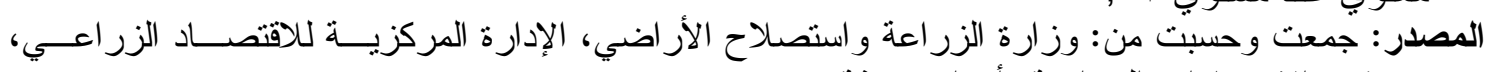

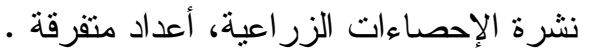

جدول رقم (1 1): تحليل (أقلّ فرق معنوي) لبيانـات متوسط إنتاج الفـــان لأهـــــ المحافظـــات المنتجة لمحصول الريحان.

\begin{tabular}{|c|c|c|c|c|c|}
\hline بني سويف & أسيوط & الفيوم & الشرقية & المنيا & المحافظة \\
\hline- & $* * \mid 0, Y)$ & $* * 17,1 \wedge$ & $* * Y,, 91$ & **ץ & بني سويف \\
\hline- & - & $\cdot, 9 \vee$. & 0,79 & 0,10 & أسيوط \\
\hline- & - & - & $\varepsilon, V Y$ & $\varepsilon, \wedge \vee$ & الفيوم \\
\hline- & - & - & - &., 107 & الثر فية \\
\hline- & - & - & - & - & المنيا \\
\hline
\end{tabular}

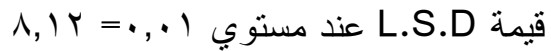

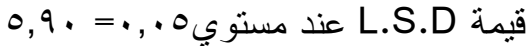

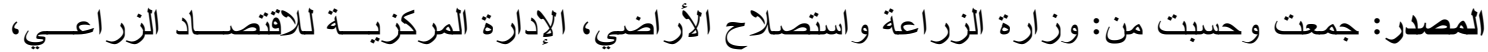

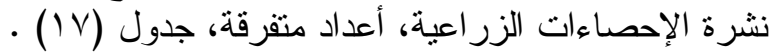

جدول (9 1): نتائج تحليل أقل فرق معنوي لترتيب المحافظات الرئيسية المنتجة للريحان وفة أرَّاً

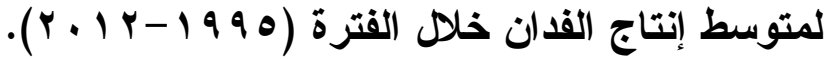

\begin{tabular}{|c|c|c|}
\hline الترتيب & متوسط إنتاج الفدان بالطن & المحافظة \\
\hline 1 & $r_{0}, r$ & بني سويف \\
\hline r & $9, \wedge)$ & أسيوط \\
\hline r & $\wedge, \wedge \varepsilon$ & 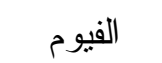 \\
\hline r & $\varepsilon, 1 Y$ & الشرقية \\
\hline$r$ & r,97 & ال امنيا \\
\hline
\end{tabular}

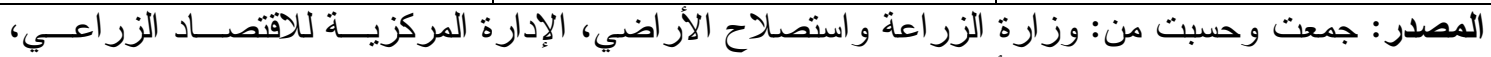

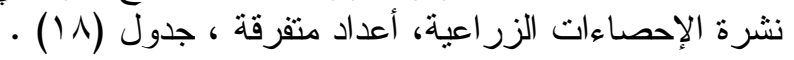

ثالثاً: الجدارة الإنتاجية للمحاصيل موضع الار اسة في محافظة أسيوط:

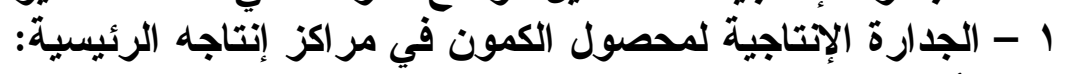

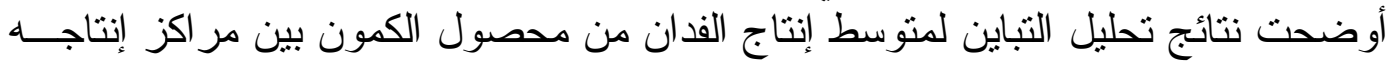
الرئيسية كما هو موضتح بالجدول (·r) إلي عدم وجود فروق مؤكدة إحصائياً بين متوسط إنتاج 


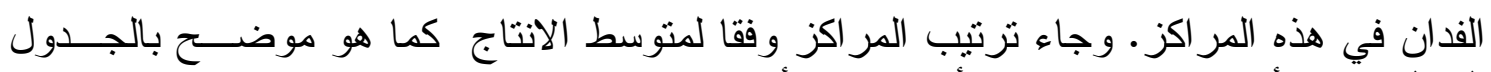

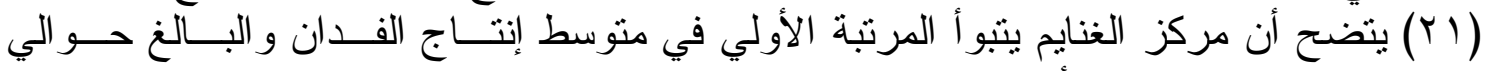

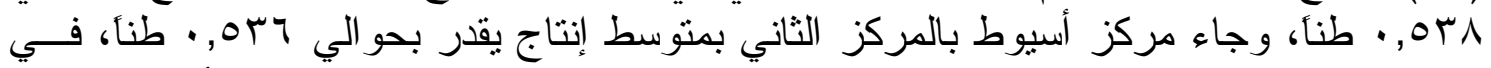

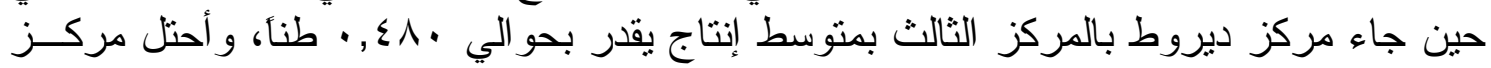

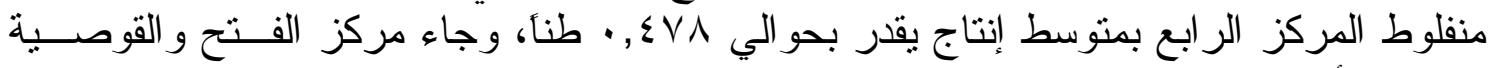

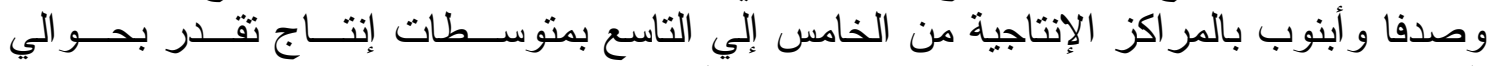
( )

جدول ( • r): نتائج تحليل التباين لمتوسط إنتاج الفدان بين المراكز الرئيسية المنتجة للكمـون

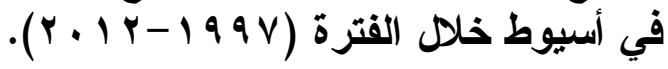

\begin{tabular}{|c|c|c|c|c|}
\hline نسبة التباين & مربوسط مجموع الاتحراف & مجموع مربعات & درجة الحرية & مصدر الاختلاف \\
\hline \multirow{3}{*}{$-1,01$} & $\cdot, \cdot\urcorner \wedge \wedge \vee$ & $\cdot, 001$ & $\wedge$ & بين المر اكز \\
\hline & $\cdot, \cdot \leq r \leq 7$ & $0, \wedge 7 \wedge$ & 1ro & داخل المر اكز \\
\hline & מrr ו & $7, \leqslant 19$ & $1 \leqslant \mu$ & المجموع الكثي \\
\hline
\end{tabular}

المصدر : جمعت وحسبت من: مديرية الزر اعة بأسيوط ، بيانات غير منشورة ، أغسطس س ا بـ.

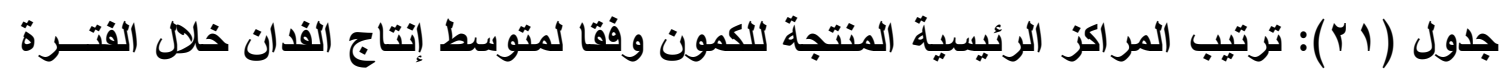
.$(r+1 r-199 \mathrm{r})$

\begin{tabular}{|c|c|c|}
\hline الترتيب & متوسط إنتاج الفدان بالطن & المركز المز \\
\hline 1 &., $0 Y \wedge$ & الغنايم \\
\hline$r$ & •, 014 & أسيوط \\
\hline r & $\cdot, \varepsilon \wedge$ & ديروط \\
\hline$\varepsilon$ & $\cdot, \Sigma \vee \wedge$ & منفلوط \\
\hline 0 & $\cdot,\{7\}$ & الفتح \\
\hline 7 & $\cdot, \varepsilon \leq \varepsilon$ & القوصية \\
\hline V & $\cdot, \varepsilon) \leqslant$ & صدفا \\
\hline$\wedge$ & $\cdot, \varepsilon \cdot 7$ & أبنوب \\
\hline 9 & • & أبو تيج \\
\hline
\end{tabular}

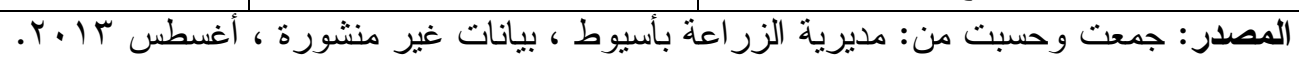

r- الجدارة الإتتاجية لمحصول اليانسون في مراكز إنتاجه الرئيسية:

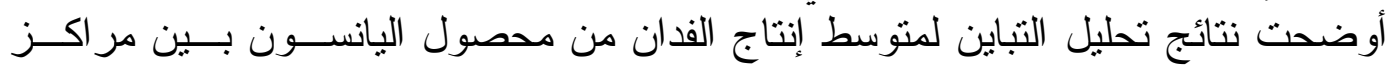

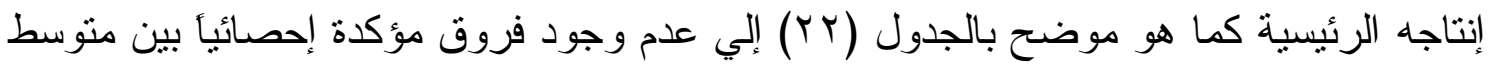

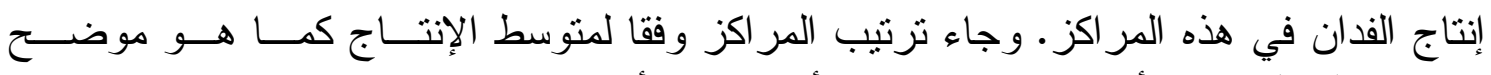

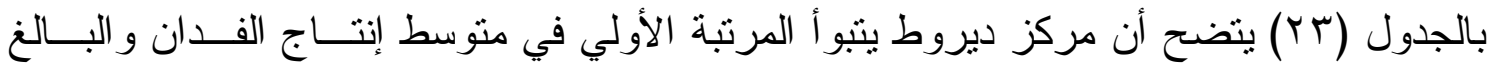

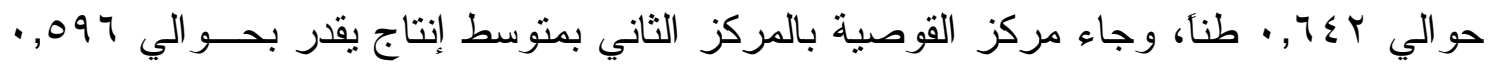

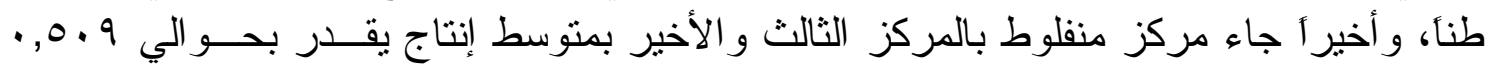


جدول (Y Y): نتائج تحليل التباين لمتوسط إنتاج الفدان بين المراكز الرئيسية المنتجة لليانسون

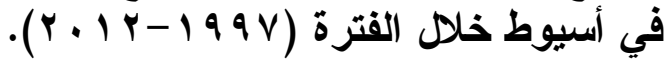

\begin{tabular}{|c|c|c|c|c|}
\hline نسبة التباين & مربعات الانحر مجموع & مجموع مربعات & درجة الحرية & مصدر الاختلاف \\
\hline \multirow{3}{*}{$-\cdot, 1 \leqslant r$} & $\cdot,+Y I$ & $\cdot, \cdot \varepsilon r$ & $r$ & بين المر اكز \\
\hline &., $10 Y$ & 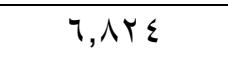 & $\leqslant 0$ & داخل المر اكز \\
\hline & $\cdot, I V r$ & ฯ, Аษ & $\leqslant V$ & المجموع الكلي \\
\hline
\end{tabular}

المصدر : جمعت وحسبت من: مديرية الزر اعة بأسيوط ، بيانات غير منشورة ، أغسطس با ـ ؟.

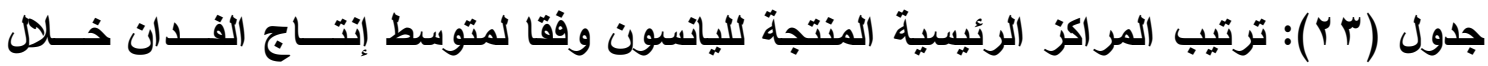

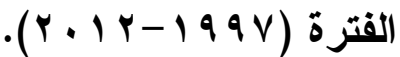

\begin{tabular}{|c|c|c|}
\hline الترتيب & متوسط إنتاج الفدان بالطن & المركز \\
\hline 1 & $\cdot, 7 \leq r$ & ديروط \\
\hline r &., 097 & القوصية \\
\hline$r$ & $\cdot, 0.9$ & منفلوط \\
\hline
\end{tabular}

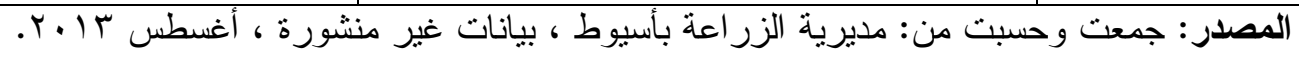

r- الجدارة الإنتاجية لمحصول الثمر في مر اكز إنتاجه الرئيسية:

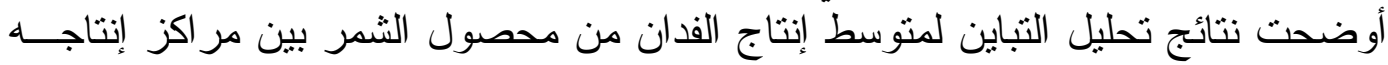

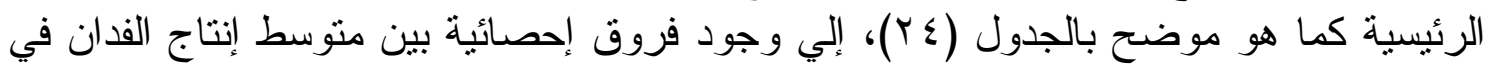

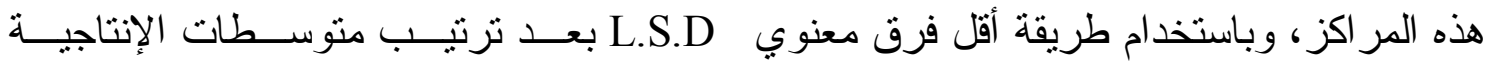
لمحصول الثمركما هو موضتح بالجدول (Yo) تنين عدم وجود فروف فرق معنوي بين منوسط إنتاجية

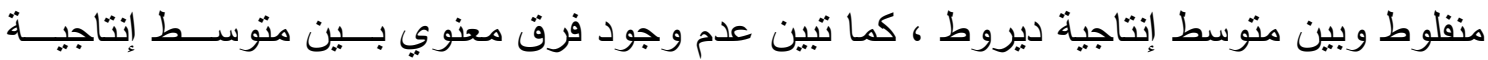

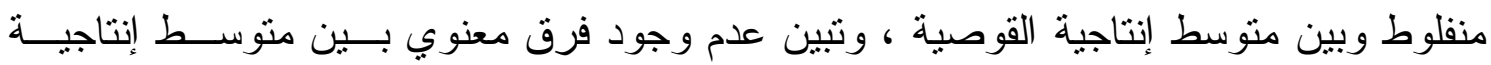

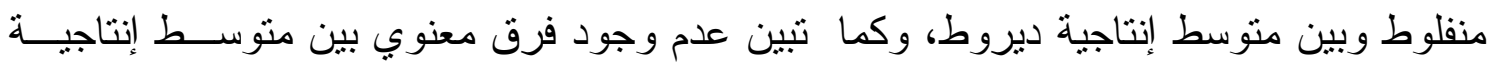

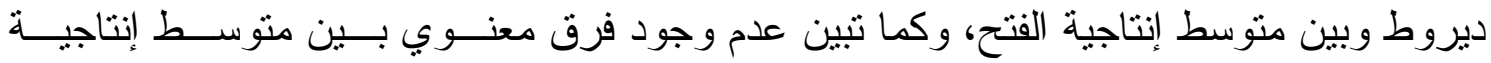

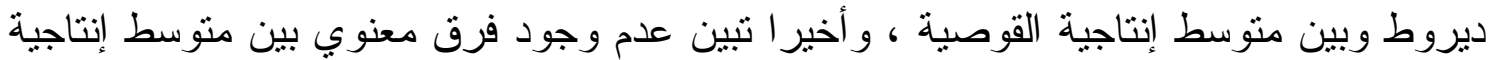

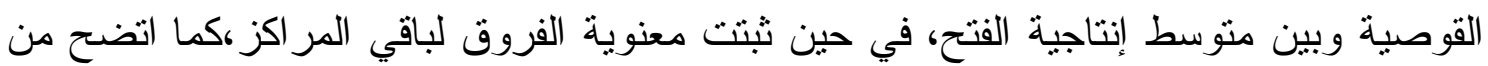

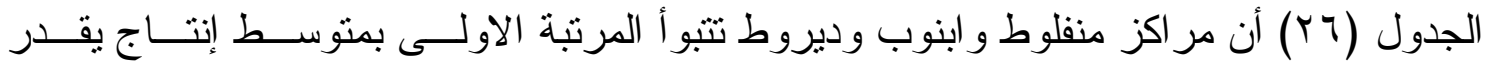

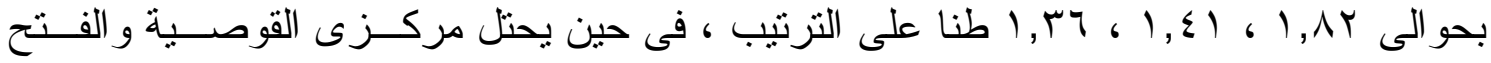

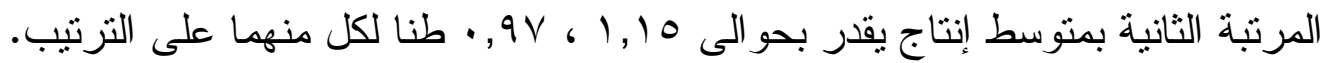

جدول (؟)): نتائج تحليل التباين لمتوسط إنتاج الفدان بين المراكز الرئيسية المنتجة للثــمر

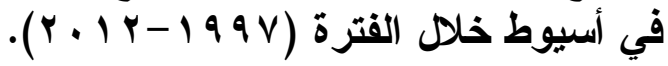

\begin{tabular}{|c|c|c|c|c|}
\hline نسبة التباين & مرتوسط مجموع مرت الاحر اف & مجموع مربعات & درجة الحرية & مصدر الاختلاف \\
\hline \multirow{3}{*}{$*$} & $1,7 Y V$ & 7,01 . & $\varepsilon$ & بين المر اكز \\
\hline & $\cdot, \varepsilon \leqslant Y$ & Tr, I 1 A & vo & داخل المر اكز \\
\hline & $r, .7 q$ & ץ, 701 & vq & المجموع الكلي \\
\hline
\end{tabular}

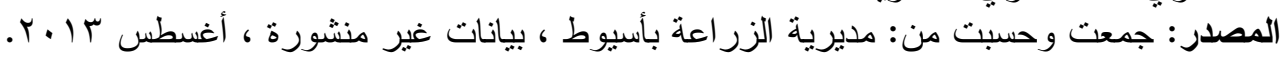




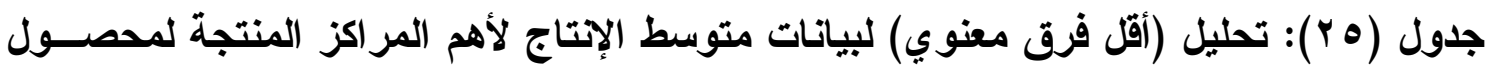

\begin{tabular}{|c|c|c|c|c|c|}
\hline أبنوب & منفلوط & ديروط & القوصية & القتح & المركز \\
\hline- & $*,, \leqslant$ OV & $*,, \leqslant 09$ & ***, ๆ & $* *, \wedge \circ$. & أبنوب \\
\hline- & - & $\cdot, .01$ & $\cdot, Y 07$ & $* \cdot, \leqslant \leqslant Y$ & منفلوط \\
\hline- & - & - & $\cdot, Y \cdot O$ & $\cdot, r q$ & ديروط \\
\hline- & - & - & - & $\cdot, 1 \wedge 0$ & القوصية \\
\hline- & - & - & - & - & الفتح \\
\hline
\end{tabular}

* معنوي عند مسنوي المعنوية 0 ., .

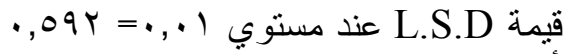

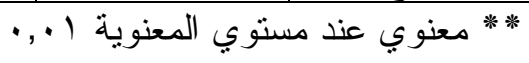

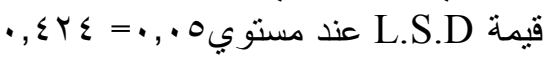

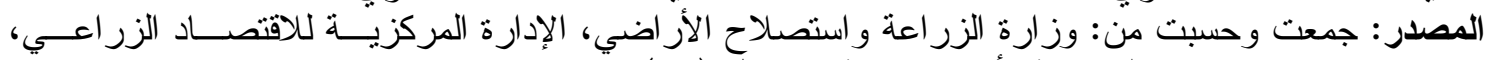

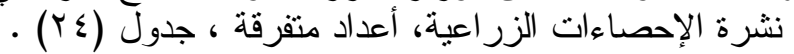

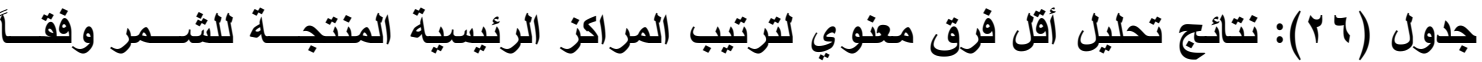

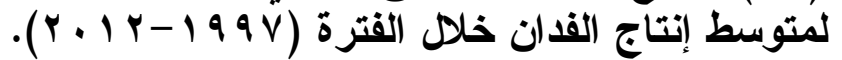

\begin{tabular}{|c|c|c|}
\hline الترتيب & متوسط إنتاج الفدان بالطن & المركز \\
\hline 1 & $1, \wedge r$ & أبنوب \\
\hline 1 & $1, \xi 1$ & منقلوط \\
\hline 1 & $1, \mu_{7}$ & ديروط \\
\hline r & 1,10 & القوصية \\
\hline$r$ & $\cdot, 9 \vee r$ & الفتح \\
\hline
\end{tabular}

المصدر: جمعت وحسبت من: مديرية الزر اعة بأسيوط ، بيانات غير منشورة ، أغسطس ب ا • Y، جـدول (Yo)

ع- الجدارة الإنتاجية لمحصول الكسبرة في مراكز إنتاجه الرئيسية:

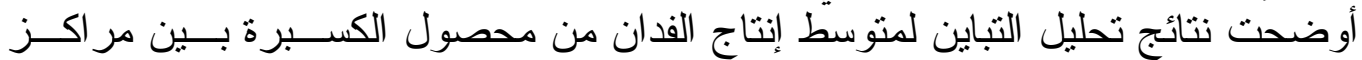

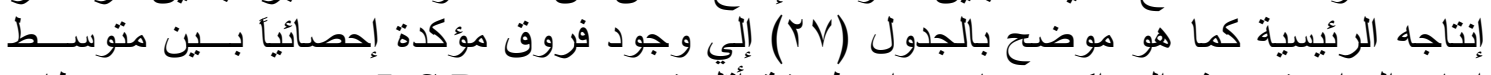

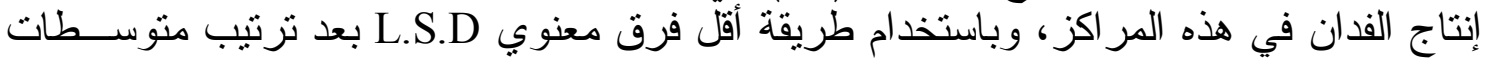

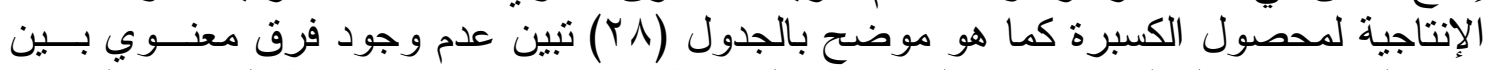

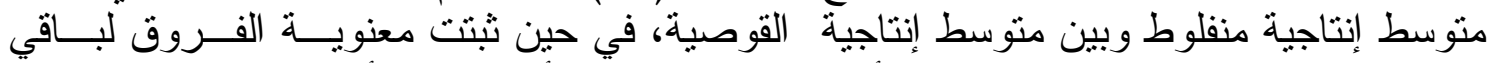

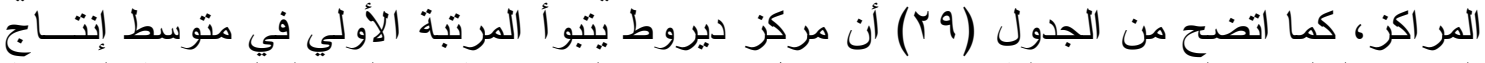

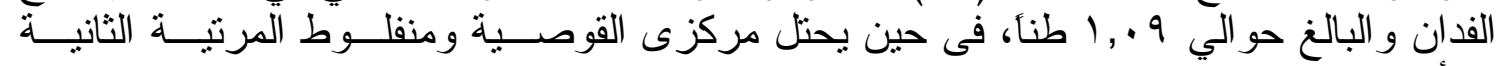

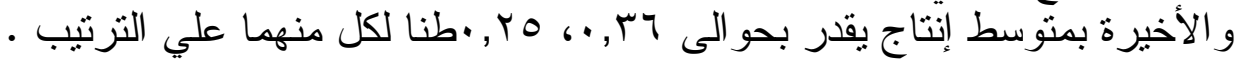

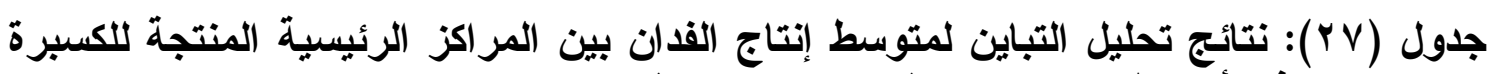

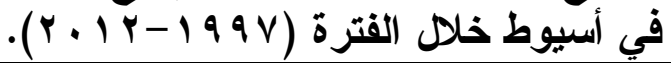

\begin{tabular}{|c|c|c|c|c|}
\hline نسبة التباين & مربعات الانحر مجموع & مجموع مربعات الإنحر اف & درجة الحرية & مصدر الاختلاف \\
\hline \multirow{3}{*}{$* * 0,0 \mathrm{~V}$} & Y,AYO & 0,70 & $r$ & بين المر اكز \\
\hline & $\cdot, 0 \cdot V$ & YY,N।q & $\leqslant 0$ & داخل المر اكز \\
\hline & r,rrr & $Y \wedge, \varepsilon V$. & $\varepsilon V$ & المجموع الكلى \\
\hline
\end{tabular}

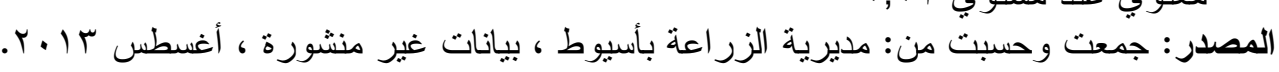

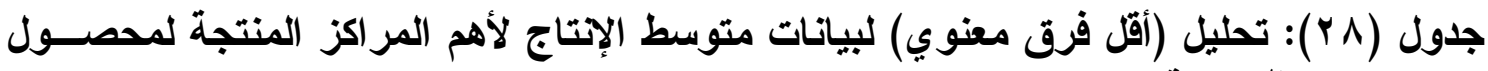

\begin{tabular}{|c|c|c|c|}
\hline & & \multicolumn{2}{|c|}{ الكسبر ه. } \\
\hline منفلوط & القوصية & ديروط & المركز \\
\hline- & - & - & ديروط \\
\hline- & - & $* *, V \mu V$ & القوصية \\
\hline- & $\cdot, 111$ & $* *, \wedge \Sigma)$ & منفلوط \\
\hline
\end{tabular}


المصدر: جمعت وحسبت من: وزارة الزر اعة و استصلاح الأر اضي، الإدارة المركزيـــة للاقتصــاد الزر اعـي، إعـي،

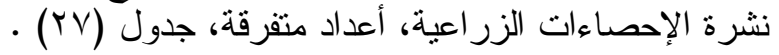

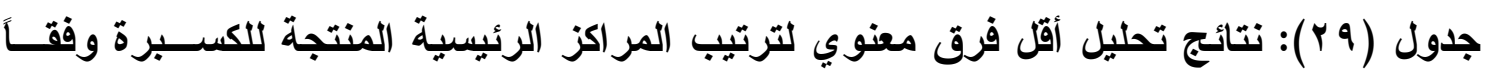

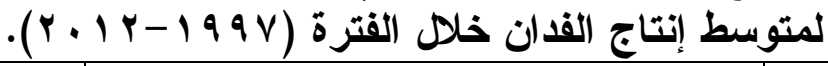

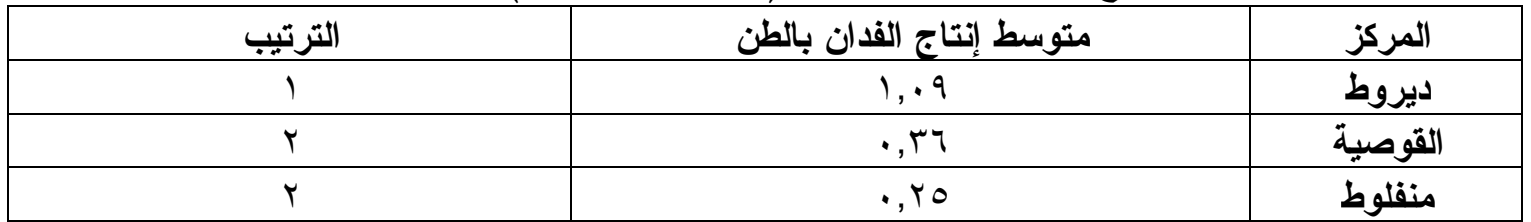

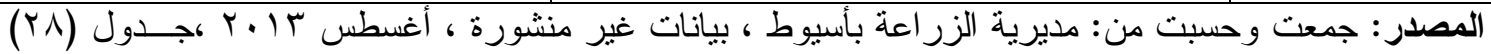

هـ الجدارة الإنتاجية لمحصول الريحان في مر اكز إنتاجه الرئيسية:

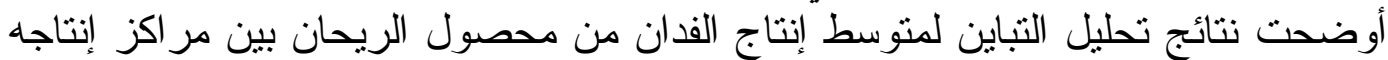

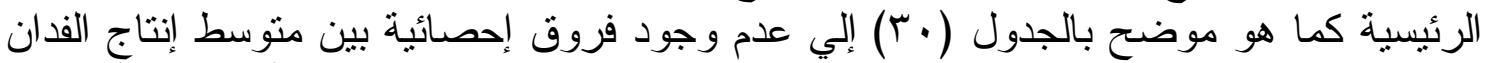

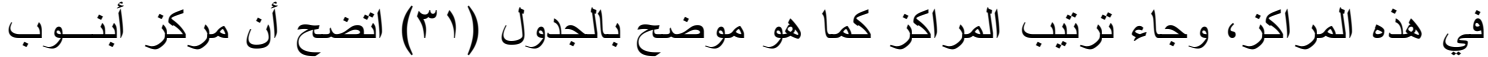

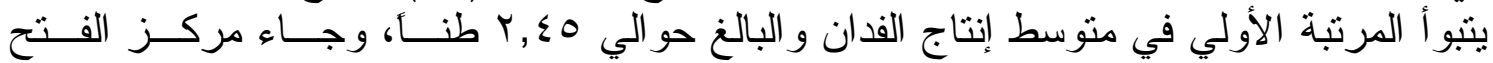

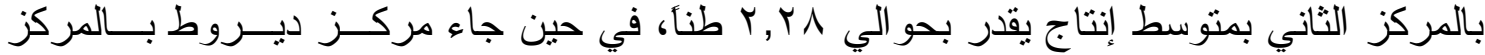

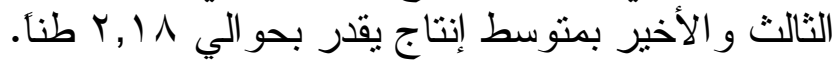

جدول ( • ب): نتائج تحليل التباين لمتوسط إنتاج الفدان بين المراكز الرئيسية المنتجة للريحان

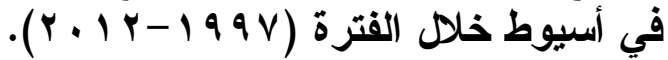

\begin{tabular}{|c|c|c|c|c|}
\hline نسبة التباين & مربعات الانحر مجوع & مجموع مربعات & درجة الحرية & مصدر الاختلاف \\
\hline \multirow{3}{*}{$-1,1 \cdot \varepsilon$} & $\cdot, \Gamma \cdot 0$ & $\cdot, 71$ & $r$ & بين المر اكز \\
\hline & $\cdot, Y \vee T$ & $1 Y, \varepsilon r \varepsilon$ & $\leq 0$ & داخل المر اكز \\
\hline & $\cdot, 0 \wedge 1$ & $\mid r, . \leq \varepsilon$ & $\leqslant V$ & المجموع الكلى \\
\hline
\end{tabular}

المصدر : جمعت وحسبت من: مديرية الزر اعة بأسيوط ، بيانات غير منشورة ، أغسطس سا بـ r.

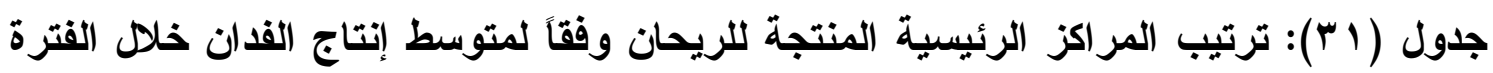
$\cdot(r \cdot 1 r-199 V)$

\begin{tabular}{|c|c|c|}
\hline الترتيب & متوسط إنتاج الفدان بالطن & 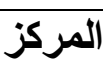 \\
\hline 1 & $r, \Sigma 0$ & أبنوب \\
\hline$r$ & $r, r_{\Lambda}$ & القتح \\
\hline r & $r, 1 \wedge$ & ديروط \\
\hline
\end{tabular}

المصدر: جمعت وحسبت من: مديرية الزر اعة بأسيوط ، بيانات غير منشورة ، أغسطس س ا . ب.

استهدف هذا البحث إلقاء الضوء ع علي تطور الإنتاج للمحاصيل موضع الإر اسة في مصر

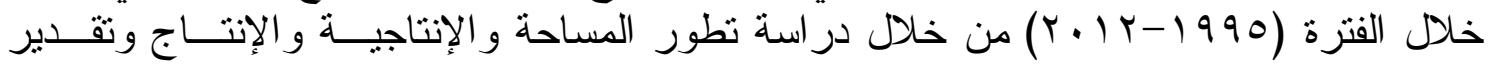

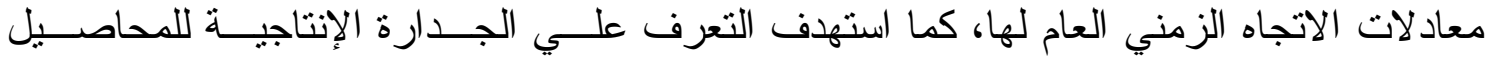

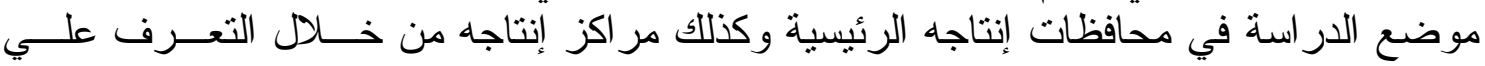

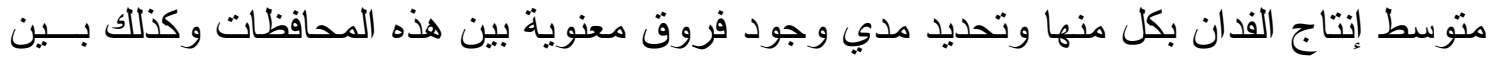

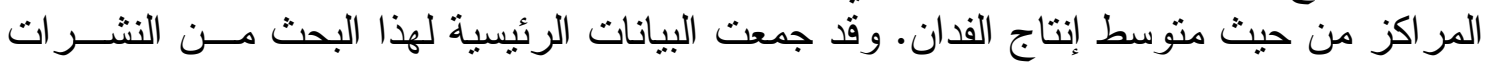

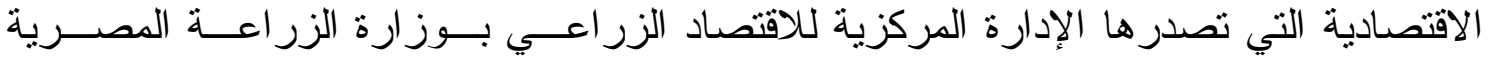

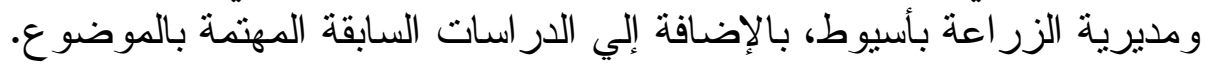
وقد انتهي البحث إلي بعض النتائج الهامة نوردها في الآتي: 
أو لا: جاءت الجدارة الإنتاجية (لمعيار منوسط انتاج الفدان) على مستوى المحافظات للدحاصيل

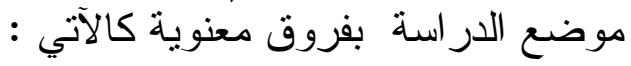

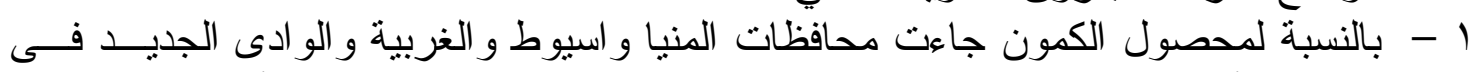

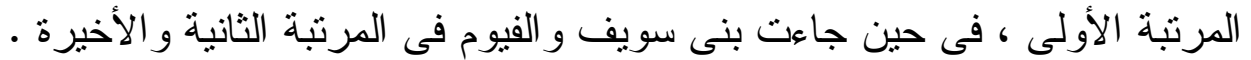

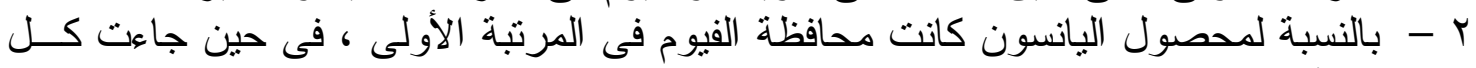

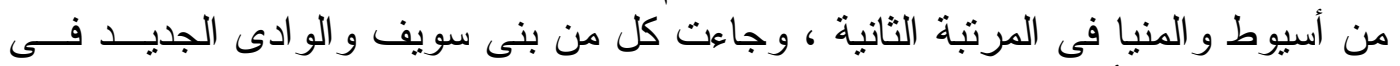

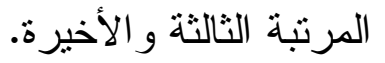

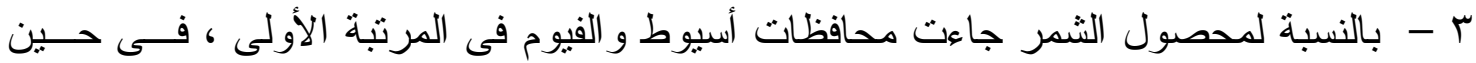

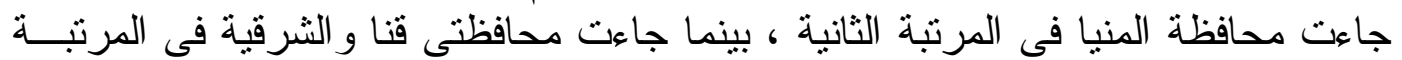

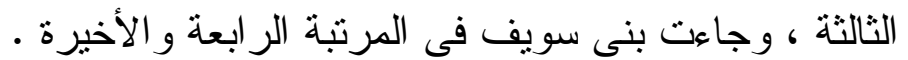

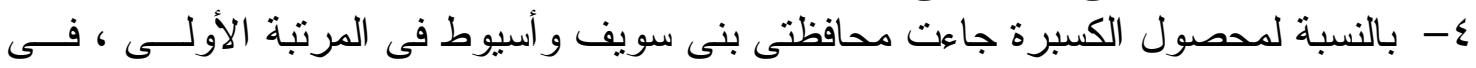

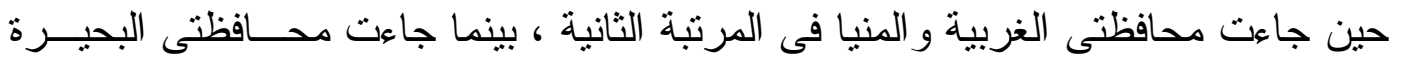
و الفيوم فى المرنبة المبنة

0 - بالنسبة لمحصول الريحان جاءت محافظة بنى سويف فى المرتية الأولى ، فى حين جاءت التهات

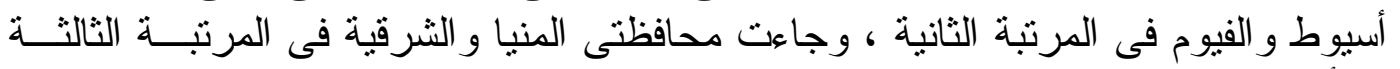

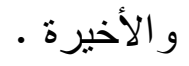
ثانيا: جاءت الجدارة الانتاجية (لمعيار منوسط انتاج الفدان) على مستوى المر اكز فى محصولى

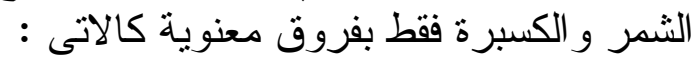

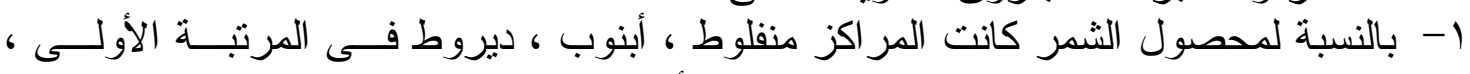
وجاءت القوصية و الفتح فى المرتبة الثانية و الأخيرة.

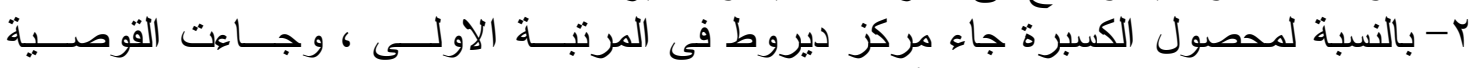
ومنفلوط فى المرتبة الثنانية و الأخيرة.

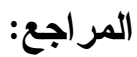

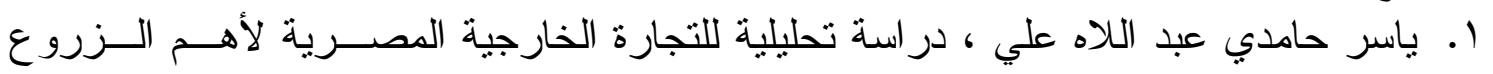

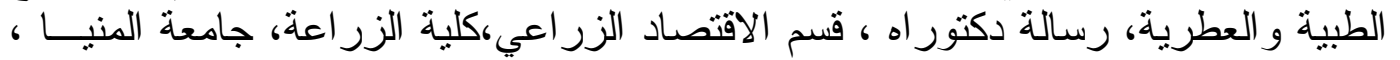
.r.1.

r. أحمد محمد أحمد (دكتور)، عبد الباقي موسي الثايب (دكتور) ، مصطفي الثحات الطوخي الثوني

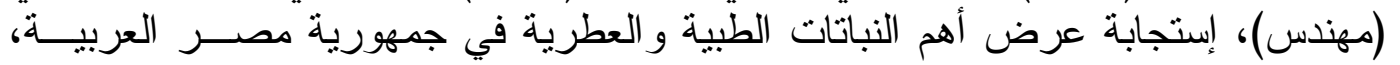

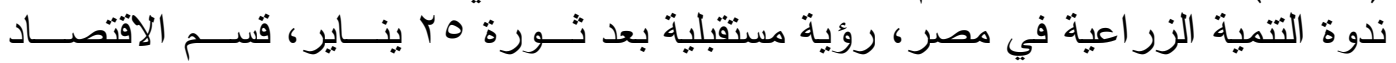

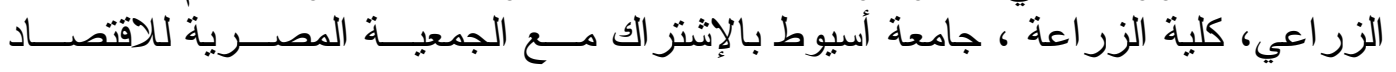

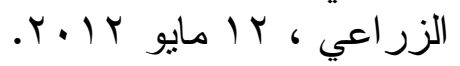

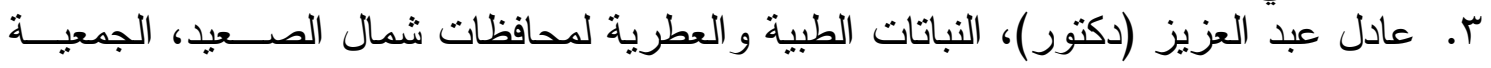

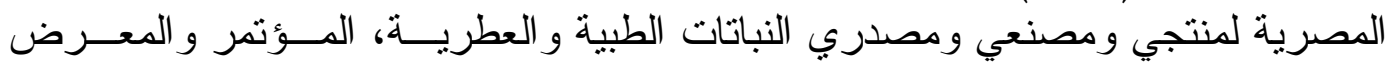

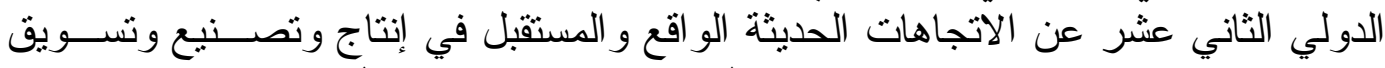

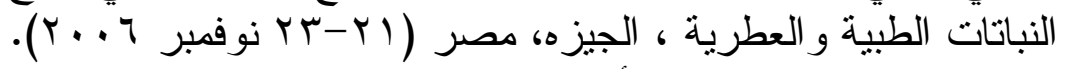

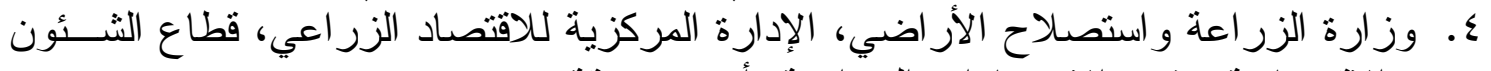

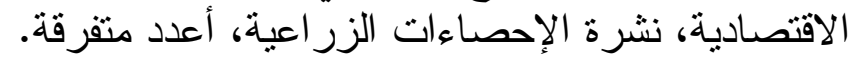
ه. مديرية الزر اعة بأسيوط ، إدارة الإحصاءة، الزراعة، اعيات غير منشورة. 


\section{An economic Study of the Merits Productivity of the Most Important Medicinal and Aromatic Plants in the Provinces of the Main Production with a Focus on Assiut Governorate}

Shima A.M. Hassan; T.H. Ismail; G.A. El-Sogheir and F.A. Amin

Department of Agricultural Economics, Faculty of Agriculture, Assiut University

\section{Summary:}

This research aimed to shed light over the evolution of the crop production which was studied in Egypt during the period (1995-2012) by studying the development of the cultivated area productivity, production and equation estimation of simple regression, also it aimed to asses production efficiency of the crops which were studied in their main production efficiency and its production districts by estimating average of feddan production, and choosing the significant differences between these governorates and between the districts concerning average of feddan production.

The current study data were taken from the bulletin issued by the central administration of the agricultural economy of the ministry of agriculture and the agriculture directorate in Assiut, in addition to the previous studies which care with this subject.

The study revealed the following findings:

First: The production efficiency for the governorates comes as a studying position with significant differences:

1- For Cumin crop, El-Minia, Assiut, El-Gharbia and New Valley were in the first class, where Bany-Sweef and El-Fayoum were in the second and final class.

2- For Anise crop, El-Fayoum was in the first class, where Assiut and ElMinia were in the second class, where Bany-Sweef and New Valley in the third and final class.

3- For Fennel crop, Assiut and El-Fayoum were in the first class, where ElMinia was in the second class, where Quena and El-Sharkia were in the third class, but Bany-Sweef was in the fourth and final class.

4- For Coriander crop, Bany-Sweef and Assiut were in the first class, where El-Gharbia and El-Minia were in the second class,where El-Behera and El-Fayoum were in the final class.

5- For Basil crop, Bany-Sweef was in the first class, where Assiut and ElFayoum were in the second class, where El-Minia and El-Sharkia were in the third and final class

Second: The production efficiency for districts for only fennel and Coriander with significant differences:

1- For fennel crop, Manfalout, Abnoub and Dairout were in the first class, where El-Kosia and El-Fateh were in the second and final class.

2- For Coriander crop, Dairout was in the first class, where El-Kosia and Manfalout were in the second and final class. 